IZA DP No. 8528

Peer Effects on Childhood and Adolescent Obesity in China

Peng Nie

Alfonso Sousa-Poza

Xiaobo $\mathrm{He}$

October 2014 


\title{
Peer Effects on Childhood and Adolescent Obesity in China
}

\author{
Peng Nie \\ University of Hohenheim
}

\author{
Alfonso Sousa-Poza \\ University of Hohenheim \\ and IZA \\ Xiaobo He \\ University of Adelaide
}

\section{Discussion Paper No. 8528 \\ October 2014}

\author{
IZA \\ P.O. Box 7240 \\ 53072 Bonn \\ Germany \\ Phone: +49-228-3894-0 \\ Fax: +49-228-3894-180 \\ E-mail: iza@iza.org
}

\begin{abstract}
Any opinions expressed here are those of the author(s) and not those of IZA. Research published in this series may include views on policy, but the institute itself takes no institutional policy positions. The IZA research network is committed to the IZA Guiding Principles of Research Integrity.

The Institute for the Study of Labor (IZA) in Bonn is a local and virtual international research center and a place of communication between science, politics and business. IZA is an independent nonprofit organization supported by Deutsche Post Foundation. The center is associated with the University of Bonn and offers a stimulating research environment through its international network, workshops and conferences, data service, project support, research visits and doctoral program. IZA engages in (i) original and internationally competitive research in all fields of labor economics, (ii) development of policy concepts, and (iii) dissemination of research results and concepts to the interested public.
\end{abstract}

IZA Discussion Papers often represent preliminary work and are circulated to encourage discussion. Citation of such a paper should account for its provisional character. A revised version may be available directly from the author. 
IZA Discussion Paper No. 8528

October 2014

\section{ABSTRACT}

\section{Peer Effects on Childhood and Adolescent Obesity in China}

Using data from the China Health and Nutrition Survey (CHNS), this study analyzes peer effects on obesity in a sample of 3- to 18-year-old children and adolescents in China. Even after a rich set of covariates and unobserved individual heterogeneity are controlled for, it is evident that such peer effects do indeed exist. These effects are stronger in rural areas, among individuals at the upper end of the BMI distribution, and especially among females. All else being equal, female adolescents whose peers have a higher BMI are less likely to consider themselves overweight, suggesting that peer effects may be working through changed societal bodyweight norms.

JEL Classification: I10, I15, J13, C14

Keywords: $\quad$ peer effects, children and adolescents, BMI, China

Corresponding author:

Alfonso Sousa-Poza

University of Hohenheim

Institute for Health Care \& Public Management

Fruwirthstr. 48

70599 Stuttgart

Germany

E-mail: alfonso.sousa-poza@uni-hohenheim.de 


\section{Peer Effects on Childhood and Adolescent Obesity in China}

\section{Introduction}

Obesity is a global public health concern not only for Western countries but also for emerging countries like China (Cheng, 2012). In China, obesity among children and adolescents is increasing sharply, with a quadrupling of obesity and a 28 fold increase in overweight among 7- to 18-year-olds within just 15 years (1985-2000) (China Daily, 2008). The prevalence of abdominal obesity in children and adolescents aged 6-17 years has also increased dramatically (Liang et al., 2012): based on the International Obesity Task Force (IOTF) criterion, general obesity and overweight increased from 6.1\% in 1993 to $13.1 \%$ in 2009 while abdominal obesity increased from $4.9 \%$ to $11.7 \%$ over the same period. Child and adolescent adiposity is even worse in some metropolitan cities like Beijing where, according to China's Working Group on Obesity (WGOC), 21.7\% of 2- to 18 years-olds were obese in 2004 (cited in Shan et al., 2010).

A large body of literature explores possible explanations for this rapid increase in childhood and adolescent obesity, including individual, social, economic, and environmental factors (de la Haye et al., 2011). One recent research stream examines the role of social networks on weight outcomes (see, e.g., Christakis and Fowler, 2007; Cohen-Cole and Fletcher, 2008), emphasizing the important role of peers in influencing the bodyweight of both adolescents and adults. Understanding such peer effects has particularly important implications for public policy design and interventions, primarily because, if peer effects do indeed exist, then preventing obesity in one individual could have a beneficial effect on others. That is, spillovers associated with social networks lead to a social multiplier effect (Christakis and Fowler, 2007).

This paper investigates whether similar peer effects on bodyweight exist in a sample of 3- to 18-year-old children and adolescents in China. In doing so it fills three research gaps. First, unlike the existing literature on peer effects and obesity, which is 
strongly dominated by research from the United States, it expands empirical investigation beyond the Western world. Such expansion is important because peer effects may well be influenced by culture, with individualistic societies being possibly less susceptible to peer effects than more collective societies (Mora and Gil, 2013). Whereas western cultures like the U.S. highlight individualism, self-autonomy, competition, and the significance of individual possessions, eastern ones like China are prone to foster cooperation, community, dependence, and relatedness (GonzalezMena, 1993). In addition, Chinese children are more strongly socialized than American children, making them more likely to be vulnerable to others' opinions, judgments, and evaluations (Fung, 1999). Differences may therefore be expected between peer effects on individual weight in Western environments like the U.S. and those in Asian environments like China. Yet to the best of our knowledge, our paper is the first to analyze peer effects on childhood and adolescent weight in rural and urban China.

Second, it broadens the almost exclusive current focus on adolescents and adults by analyzing children as well. This lack of research on the young is surprising given the wide recognition in the consumer science literature that young children's consumption decisions are affected by those of their peers (Dishion and Tipsord, 2011). If such peer effects do exist, they could be especially important in that eating habits are formed at a young age (Kelder et al, 1994; Schwartz et al., 2011). Third, by allowing us to assess whether a relation exists between peer obesity and individual perceptions of weight status - on which there is as yet little evidence - our data enable closer examination than in prior studies of the mechanisms through which peer effects might work.

Overall, our results show not only that peer effects exist among Chinese children and adolescents aged 3 to 18 years but that such effects are stronger among females than among males, in rural than in urban areas, and among individuals at the upper end of the BMI distribution. Our results also support the notion that peer BMI affects individual bodyweight perceptions.

The remainder of the paper proceeds as follows: Section 2 reviews the relevant literature. Section 3 describes the identification issues for peer effects, our identification strategy, and our analysis of underlying mechanisms. Section 4 outlines 
the data and methods. Section 5 reports the results of the empirical analysis and robustness checks, and Section 6 concludes the paper.

\section{Prior research}

The relevant studies analyzing peer effects on obesity are listed in Table 1 . The seminal study by Christakis and Fowler (2007) confirms the existence of a socialnetwork multiplier effect. Using data from the 32-year Framingham Health Study (1971 to 2003), they show that adults are 57\% more likely to be obese if their friends become obese. Several other studies based on the National Longitudinal Study of Adolescent Health (Add Health) dataset also reveal a positive association between peer effects and adolescent obesity (Cohen-Cole and Fletcher, 2008; Fowler and Christakis, 2008; Renna et al., 2008; Trogdon et al., 2008; Halliday and Kwak, 2009; Yang and Huang, 2010). On the other hand, when Cohen-Cole and Fletcher (2008) use the Add Health data to replicate Christakis and Fowler's (2007) findings, their results, although they do not rule out the possibility of peer effects, suggest that community-level factors can explain a large share of the peer effect. The authors also argue that "shared environmental factors can cause the appearance of social network effects” (Cohen-Cole and Fletcher, 2008, p. 1386). Fowler and Christakis (2008), however, in a rebuttal of this study also based on Add Health data, provide further evidence for the existence of peer effects.

Renna et al. (2008) show that a higher BMI in close friends is associated with higher adolescent BMI, and adolescents are more responsive to the body weight of their same gender friends. This observation is confirmed for the U.S. by Larson et al. (2013), whose analysis of the 2010 Eating and Activity in Teens (EAT) survey in Minnesota suggests that the proportion of overweight friends is correlated with higher adolescent BMI. ${ }^{1}$ Likewise, Halliday and Kwak (2009), using Add Health data, confirm a strong correlation between peer and individual BMI, while Trogdon et al. (2008), in a study of same-grade school peer groups, show that peer effects on

\footnotetext{
1 The Eating and Activity in Teens (EAT) survey polls 2,793 adolescent respondents (with an average age of
} 14.4 years), approximately $46 \%$ of whom are in middle school and about $54 \%$ in high school. 
adolescent weight do exist and are stronger for both individuals with a higher BMI and for females.

Another perspective is offered by Yang and Huang (2013), whose examination of asymmetric peer effects on individual weight indicates that although individual weight gain is associated with having more friends that are obese, weight loss is not correlated with having fewer obese friends. The existence of persistent peer effects on individual weight outcomes is further confirmed by Ali et al.'s (2012) study of the peers' dynamic effects on adolescent weight, which also shows that they lead to individual weight gain. The only study that we are aware of that provides causal evidence is that of Yakusheva et al. (2014) that uses a sample of first-year college students.

Table 1: Summary of recent studies of peer effects on individual bodyweight

\begin{tabular}{|c|c|c|c|c|c|c|}
\hline Authors (year) & Data source & Country & Targets & $\begin{array}{c}\text { Peer } \\
\text { definition }\end{array}$ & Methods & Outcomes \\
\hline $\begin{array}{l}\text { Christakis \& Fowler } \\
\text { (2007) }\end{array}$ & $\begin{array}{l}\text { Framingham } \\
\text { Health Study }\end{array}$ & U.S. & Adults & $\begin{array}{l}\text { Self- } \\
\text { nominated } \\
\text { friends, } \\
\text { siblings, } \\
\text { spouse, and } \\
\text { neighbors }\end{array}$ & LLM & Positive \\
\hline $\begin{array}{l}\text { Cohen-Cole \& } \\
\text { Fletcher (2008) }\end{array}$ & Add Health & U.S. & Adolescents & $\begin{array}{l}\text { Self- } \\
\text { nominated } \\
\text { friends }\end{array}$ & $\begin{array}{l}\text { OLS } \\
\text { Logit }\end{array}$ & Positive \\
\hline Renna et al. (2008) & Add Health & U.S. & Adolescents & $\begin{array}{c}\text { Self- } \\
\text { nominated } \\
\text { friends }\end{array}$ & OLS/IV & Positive \\
\hline Trogdon et al. (2008) & Add Health & U.S. & Adolescents & $\begin{array}{c}\text { Self- } \\
\text { nominated } \\
\text { friends; } \\
\text { Students } \\
\text { within the } \\
\text { same grade }\end{array}$ & $\begin{array}{c}\text { OLS/TSLS } \\
\text { Probit/TSLS- } \\
\text { Probit QR }\end{array}$ & Positive \\
\hline $\begin{array}{l}\text { Fowler \& Christakis } \\
\text { (2008) }\end{array}$ & Add Health & U.S. & Adolescents & $\begin{array}{c}\text { Self- } \\
\text { nominated } \\
\text { friends }\end{array}$ & OLS/FE/MC & Positive \\
\hline
\end{tabular}


Halliday \& Kwak (2009)

$\begin{array}{lc}\text { Valente et al. (2009) } & \begin{array}{c}\text { In-school } \\ \text { survey, Los } \\ \text { Angeles }\end{array} \\ & \begin{array}{c}\text { The study from } \\ \text { a private } \\ \text { Yidwestern } \\ \text { Yakusheva et al. }\end{array} \\ \text { (2011) } & \text { university } \\ & \text { The study from } \\ \text { Yakusheva et al. } & \text { two universities } \\ \text { (2014) } & \text { (private/public) }\end{array}$

Larson et al. (2013)

Yang \& Huang

(2013)

Asirvatham et al.

(2013a)

EAT 2010

Add Health

U.S.

Adolescents

Self-

nominated friends

Selfnominated friends

U.S. Adolescents

Arkansas Center for Health Improvement

(Arkansas)

Children

Arkansas

Asirvatham et al. (2013b)

Center for

Health

Improvement

A public high-

de la Haye et al.

(2011)

school survey

in a major

Australian city

Australia

Adolescents

Self-

nominated

(12.3-15.6 yrs) best friends

SAOMs

No

effects

Leatherdale \&

Papadakis (2011)

SHAPES

Canada

Adolescents

Senior

students

(grades 11 and 12)

within the

same 
school

A secondaryschool student survey, Catalonia

Mora \& Gil (2013)

Loh \& Li (2013)

CHNS
Spain

Adolescents

(14-18 yrs)

Self-

nominated

friends

within the

OLS/GMM/LIML Positive

same

classroom

Children in

the same

age group,

level of

Adolescents

Rural China

school and

community;

OLS/2SLS/QR Positive

children in

the same

age group

and

community

Note: Add Health $=$ the National Longitudinal Study of Adolescent Health; EAT $=$ the Eating and Activity in Teens in 2010; and SHAPES = the School Health Action, Planning, and Evaluation System. The estimation methods are as follows: Logistic= logistic model; LLM=longitudinal logistic-regression model; Ologit= ordered logit model; Probit= probit model; TSLS= two stage least squared model; IV-Probit= instrumental variable probit model; RE-Logistic= random effects logistic model; $\mathrm{ERGM}=$ exponential random graph model; SAOMs= stochastic actor-oriented model; $\mathrm{FE}=$ fixed effects model; $\mathrm{RE}=$ random effects model; $\mathrm{MC}=$ Monte Carlo simulations; $\mathrm{QR}=$ quantile regression model; $\mathrm{NE}=$ natural experiment method (using random roommate assignments); GMM= general method of moments model; LIML=limited information maximum likelihood model; and $\mathrm{MR}=$ mean regression.

As Table 1 suggests, we know of only a handful of studies on this topic outside the U.S. Among these, Leatherdale and Papadakis (2011), using cross-sectional data from the Physical Activity Module (PAM) of the School Health Action, Planning, and Evaluation System (SHAPES) in Ontario, Canada, confirm that the likelihood of overweight or obesity for junior students (grades 9 and 10) is significantly influenced by the prevalence of obesity among senior students (grades 11 and 12). Likewise, Mora and Gil (2013), using a sample of secondary school students in Catalonia, Spain, identify a positive and significant casual effect of friend's mean BMI on an adolescent's BMI. $^{2}$ An Australian study by de la Haye et al. (2011), however, based on a four-wave dataset from a public high-school in a major Australian city, finds no

2 Mora and Gil (2013) use ordinary least squared (OLS), general method of moments (GMM), and limited information maximum likelihood (LIML) estimations to evaluate the causal relation between adolescent BMI and friend mean BMI. In the GMM and LIML estimates, the IV candidates include mother's education, mean age, and the share of single or divorced parents of the respondents' friends-of-friends who are not friends with the respondent. 
correlation between adolescents’ BMI and that of their friends. ${ }^{3}$ In perhaps the only study outside the Western domain, Loh and $\mathrm{Li}(2013)^{4}$ draw on data from the 2000 China Health and Nutrition Survey (CHNS), which targets individuals aged 10-19 years living in urban areas, to show that peer effects on adolescents' BMI also exist in the Chinese sample and are particularly strong at or below median BMI and among females.

Given our research aim, it is important to highlight three aspects of past research: First, virtually no research exists on peer effects among children (as opposed to adolescents and adults). To the best of our knowledge, only the unpublished Arkansas study shows that peer effects are significantly correlated with childhood obesity (Asirvatham et al., 2013a; 2013b). Second, research seldom explores the underlying mechanisms of such an effect, even though, as An (2011) emphasizes, knowing how peer effects translate into individual obesity would throw light on the specific pathways through which peer effects work; for example, the influence of peers on dietary patterns, physical activities, and perceptions of body weight. One possible exception is Blanchflower et al.’s (2009) analysis of data from the Eurobarometer and the German Socioeconomic Panel (GSOEP), which shows that self-perception of overweight is affected by an individual's BMI relative to a broadly defined peer group. Finally, although nonlinear peer effects seem to exist in other domains, little is known about the potentially nonlinear relation between peer effects and individual obesity. ${ }^{5}$ These three points highlight the contributions of our study: not only is it one of the

3 De la Haye et al. (2011) apply stochastic actor-oriented models (SAOM) to a sample of 156 students aged 12.3 to 15.6 years to evaluate the role of adolescents' friend selection and the possible influences of friends' BMI on changes in individual BMI.

4 On the other hand, numerous studies analyze the effects of peers on other individual outcomes in China. For example, based on the China Health and Nutrition Survey, Li et al. (2013) examine the influence of peers on children's school dropout rate in rural China, suggest that this rate would increase 0.39 to 0.50 percent if peers' dropout rates increased by 1 percent. Ding and Lehrer (2007), in a study of peer influences on the academic outcomes of secondary school students, find strong evidence of the presence of peer effects but in a positive and nonlinear form. Similarly, Carman and Zhang (2012) suggest that peer effects are significantly positive for the math test scores of middle school students but insignificantly positive for Chinese test scores and have no influence on English test scores. Using data from a Chinese college, Han and Li (2009) investigate residential peer effects on higher education and find that only female academic achievements (GPA) are responsive to the effects of peers' academic results (College Entrance Test rankings). They find no peer effects on becoming a Communist Party member. Kato and Shu (2009) also provide evidence for the presence of peer effects in the manufacturing workplace in China, showing that workers are more likely to improve performance if they are working with more capable teammates. Another interesting study, conducted by Chen et al. (2008) using the Chinese Household Income Project Survey (CHIP) 2002, presents evidence that peer effects significantly increase individual migration.

5 Based on CHIP data, Chen et al. (2008) examine the nonlinear pattern of peer effects on migration decisions in rural China. Ding and Lehrer (2007) uses semiparametric methods to confirm the nonlinearity of peer effects on the academic outcomes of secondary school students in one county of Jiangsu province in China. 
first to focus on children as well as adolescents, it also examines peer effects in a nonWestern environment, sheds initial light on the transmission mechanisms through which peer effects may work, and takes a detailed look at possible nonlinear peer effects on obesity.

\section{Identification of peer effects and analysis of mechanisms}

Despite a wealth of studies on peer effects, because of methodological difficulties in specifically identifying the effects themselves, little consensus exists on their importance and magnitude (Manski, 1993). More specifically, an individual’s obesity might be associated with that of a peer group because of a causal (or endogenous) effect, contextual (exogenous) effect, correlated effect, or selection effect. The first refers to a direct effect of the peer group on the individual, while the second recognizes that an individual's bodyweight could be influenced by peer group characteristics other than bodyweight. The third acknowledges that both the individual's and the peers' bodyweight may be influenced by some unobservable factors (e.g., required physical exercise at school), and the fourth accounts for the possibility that obese individuals may select friends that are themselves obese. It is particularly worth noting that if a correlation between individual and peer-group obesity emanates from one of the last three effects, then interventions aimed at reducing obesity are less likely to result in the oft-cited social spillover effect (Trogdon et al., 2008). In this section, therefore, we define our peer-group concept and explain how we intend to identify these different effects. We also outline our approach to identifying the underlying mechanisms.

\section{Definition of peers}

Although the literature suggests many different peer group compositions, including respondent-identified friends, classmates, roommates, and neighbors (see Table 1 above), it is in essence possible to distinguish between broad (e.g. grade-level) and narrow (e.g. friend-level) peer definitions. Whereas broad definitions capture changes in norms and social attitudes, narrower definitions need not do so and may instead operate through influences on diet and physical activity (Trogdon et al., 2008). In our 
study, we use a broad peer group; namely, children in a similar age group within a specific community.

\section{Contextual effects/exogenous effects}

As pointed out above, an individual's bodyweight may be affected by unobservable characteristics of the peers, such as their family and cultural backgrounds (Yakusheva et al., 2011), which would bias a direct peer effect. We therefore employ a rich set of household, community, and provincial variables to capture diverse characteristics of the peer reference group.

\section{Correlated effects/reflection problem}

Correlated effects imply that common environments and institutions might simultaneously affect the bodyweight of both individuals and their peers. It is thus important that any investigation into the relation between peer effects and individual obesity take into account potential confounders (Yakusheva et al., 2011). We do so by including a very rich set of community-level variables, including food prices and the availability of fast food restaurants and recreational facilities (gym/exercise centers, park/public recreation places, playgrounds) in the community. We also include provincial dummies that capture unobservable factors like geographic and climate conditions, which do not vary across time. Such community-level variables control for a common environment at the community level, one shared by both the individuals and their peer groups. We also control for correlated effects stemming from unobservables at the community level using fixed effects models.

\section{Selection effects}

Given that individuals can generally choose their friends, roommates, or neighbors, it is sometimes difficult to disentangle peer selection from peer influence, which might lead to an overestimation of peer effects (Fletcher, 2011). In our case, however, because peer groups are defined at the community level, it seems unlikely that peer selection is an issue (as in Trogdon et al., 2008). Furthermore, the Chinese Hukou system has considerably inhibited the free choice of residential community ( $\mathrm{Lu}$ and Wan, 2014), thereby strongly mitigating the selection issue. 
Analysis of underlying mechanisms

When the analysis uses a broad peer-group measure like ours, the peer effect may work via its influence on accepted BMI norms or BMI standards for bodyweight in a community (Burke and Heiland, 2007). In this present study, therefore, we also analyze adolescents' perceptions of bodyweight; more specifically, whether selfreported perceptions of weight status - underweight, normal weight, or overweight - is affected by peer BMI. If peer BMI affects norms or standards, then this effect may be captured by individuals' perceptions of their own bodyweight. All else being equal (especially with regards to individual BMI), individuals whose peers have a higher BMI should be less likely to consider themselves overweight. Analyzing such perceptions could provide strong evidence for the existence of peer effects. That is, although it is difficult to ensure that all contextual and correlated effects have been accounted for in an analysis of the relation between peer and individual BMI, such effects are unlikely to be the drivers of any correlation between peer BMI and individual bodyweight perceptions.

\section{Data and methods}

\section{Survey and sample}

Our data are taken from the China Health and Nutrition Survey (CHNS), which has been conducted in nine waves (1989, 1991, 1993, 1997, 2000, 2004, 2006, 2009 and 2011). ${ }^{6}$ The survey sample is drawn from nine provinces (Liaoning, Heilongjiang ${ }^{7}$, Jiangsu, Shandong, Henan, Hubei, Hunan, Guangxi and Guizhou) with different social, economic, and health situations. The survey's multistage random cluster sampling method, which is based on different income levels (high, medium, and low) and weighted sampling, entails the following steps: After randomly selecting four counties and two cities within each province, the CHNS randomly identifies villages and towns in each county and urban and suburban regions in each city. It then selects 20 households from each of these communities, which in 1989 and 2009 numbered

6 Our analysis goes only through 2009 because the 2011 data for individual weight and height are currently unavailable.

7 Heilongjiang province was introduced as the ninth province in 1997, but Liaoning province did not participate in that year because of natural disasters at the time. 
190 and 218, respectively (see Popkin et al., 2011, for a detailed description of the CHNS dataset).

In the present study, the data for the empirical analysis include the three waves for 2004, 2006, and 2009, primarily because the information on recreational facilities in the community (such as the availability of playgrounds) has only been available since 2004. After we drop missing values for the control variables, our selected sample comprises 2,186 children and adolescents aged 3-18 years. To identify any potential heterogeneity of peer effects on bodyweight for these subjects, we analyze three age groups separately: 3- to 18-year-olds (all), 3- to 9-year-olds (children), and 10- to 18year-olds (adolescents). ${ }^{8}$ Because of limited availability of data on self-reported perceptions of bodyweight, ${ }^{9}$ our pathway analysis is restricted to adolescents aged 10 to 18 years.

\section{Peers}

We broadly define peers as all individuals in the same age band and same community, excluding the target individual $i$ (for a similar definition, see Loh and Li, 2013). We divide the individual age bands into five groups, 3-5, 6-8, 9-11, 12-14, and 15-17 years, and calculate the leave-out average BMI peer effects ${ }^{10}$ as follows:

$$
\overline{B M I}_{(i) j c}=\left(\sum B M I_{i j c}-B M I_{i j c}\right) /\left(N_{j c}-1\right)
$$

where $B M I_{i j c}$ designates individual $i$ 's BMI in age band $j$ and community c. $\overline{B M I}_{(i) j c}$ denotes the average BMI of peers in age band $j$ and community $c$ without individual $i$, and $N_{j c}$ indicates the sample size of individuals in age band $j$ and community $c$.

When analyzing individual perceptions, we slightly adjust the age ranges in order to focus on adolescents (i.e., those between 10 and 18). Specifically, we define the age bands as follows: $10-11,12-13,14-15$, and 16-17 years.

\section{Dependent variables}

\footnotetext{
8 Here, the age cutoff of 10 years for children and adolescents is based on a WHO criterion. Specific descriptions are available from http://www.who.int/topics/adolescent_health/en/.

9 In the CHNS, information on self-reported perceptions of bodyweight is available for children aged $\geq 6$ years from wave 2000 onwards.

10 For an interesting discussion of leave-out and full average peer effects, see Angrist (2013).
} 
The dependent variables of interest are individual BMI and self-reported perception of bodyweight. The survey calculates child or adolescent BMI as individual weight (in kilograms) divided by squared height (in meters), all measured and recorded by professional health workers. Self-reported perception of individual weight is based on the following question:

Do you think you are now underweight, normal, or overweight? $0=$ underweight; 1 =normal; 2 =overweight; $9=$ unknown

We drop any observations of self-reported perception of weight with a value of 9 (unknown).

As a robustness check, we also employ BMI z-scores based on growth charts from the International Obesity Task Force (IOTF) (Cole et al., 2000), which, being based on a broad set of countries that includes Hong Kong, is more appropriate for evaluating Chinese overweight and obesity than alternative growth charts (see, e.g., Monasta et al., 2010). As a further robustness check, we also use waist circumference as an alternative anthropometric measure of obesity.

The independent variables are categorized into three groups: individual, family and mother, and community variables.

\section{Individual controls}

Our specifications include two individual variables: age and gender. The gender dummy equals 1 if the individual is a male, 0 otherwise.

\section{Family and mother controls}

Five variables make up the controls for family and mother: mother's BMI, mother's education level, mother's employment status, household per capita income (i.e., total household income divided by household size) adjusted to 2011, and household size. Mother's BMI is mother's weight (in kilograms) divided by squared height (in meters), and mother's education level is measured by years of schooling. The dummy for mother's employment status equals 1 if the mother is currently working, 0 otherwise. 


\section{Community controls}

The community controls are divided into four subgroups measured by dummy variables: public schools, fast food restaurants, recreational facilities, and real food prices in the community. Dummy variables for public schools (primary school, lower middle school, and upper middle school) in the community equal 1 if this type of school is present in the community, 0 otherwise. The dummy variable for fast food restaurants is equal to 1 if a fast food restaurant is available nearby, 0 otherwise. Dummy variables for public recreational facilities -including gym/exercise centers, park/public recreation places, and playgrounds - all equal 1 if such recreation facilities are accessible in the community, 0 otherwise. We also control for 20 different food prices ${ }^{11}$ (yuan/kilograms, adjusted to 2011) in the free markets near the community, including rice, bleached flour, unbleached flour, corn flour, millet, sorghum, rapeseed oil, soybean oil, peanut oil, sugar, eggs, commonly eaten vegetables, pork, chicken, beef, mutton, fresh milk, milk powder, fish, and beancurd.

\section{Estimation strategies}

We begin with an OLS model of the following form:

$$
B M I_{i j c}=\beta_{0}+\beta_{1} \overline{B M I}_{(i) j c}+\beta_{2} X_{i c}+\beta_{3} F_{i c}+\beta_{4} Z_{c}+\beta_{5} W_{c}+\beta_{6} P_{c}+\varepsilon_{i c}
$$

where $X_{i c}$ is a vector of individual $i$ 's characteristics, $F_{i c}$ is a vector of family and mother characteristics, $Z_{c}$ is a vector of community characteristics, and $W_{c}$ is a vector of the year dummy (with 2004 as the reference year). $P_{c}$ is a vector of the province dummy (with Liaoning as the reference province), $\varepsilon_{i c}$ is the individual-specific error term, and $\beta_{1}$ is the coefficient representing the effect of peers on child/adolescent BMI. The correlated effects are captured mainly by the coefficient $\beta_{4}$, which represents the impact of shared community environments on both individual weight and peer effects.

To examine whether the mean peer BMI has a different impact on different points of the individual BMI distribution conditional on the covariates, we use quantile

\footnotetext{
11 It is worth noting that there are three major sources of price information in CHNS: free market prices, stateowned store prices, and authorities' price records (Guo et al., 2000). Since 1989, however, state-owned stores have been gradually replaced by free markets and supermarkets, and most food is currently accessible on the free market (Du et al., 2004). We thus employ free market prices (adjusted to 2011).
} 
regressions estimated at the 25th, 50th, and 75th percentiles using the same specifications as in the OLS model. We also investigate whether the mean peer BMI influences adolescents' self-reported perception of bodyweight by applying an ordered probit model to these same specifications.

Although we control for numerous community-level covariates associated with individual bodyweight, there may still be some unobservables present in the community or province. Hence, we also employ fixed effects models to control for any unobservable time-invariant heterogeneity related to individual bodyweight. Specifically, we construct pairs of observations for individuals surveyed in two years, pool these pairs (group 1: 2004 and 2006; group 2: 2004 and 2009; and group 3: 2006 and 2009), and then run fixed effects estimations using two group dummy variables (with group 3 as the reference group). We can remove individual time-invariant effects through first differencing. The model to be estimated is thus

$$
B M I_{i j c}=\theta_{0}+\theta_{1} \overline{B M I}_{(i) j c}+\theta_{2} X_{i c}+\theta_{3} F_{i c}+\theta_{4} S_{c}+\theta_{5} G_{t}+\alpha_{i}+\varepsilon_{i c t}(2)
$$

Where $S_{c}$ is food prices on the free market, $G_{t}$ is a vector of group dummy variables, $\alpha_{i}$ is the individual time-invariant fixed effect, and $\varepsilon_{i c t}$ is the idiosyncratic error term.

\section{Results}

\section{Descriptive statistics}

As appendix Table A1 shows, the mean BMI of children and adolescents aged 3-18 years is 16.61 , the average BMI $z$-score is -0.15 , and the average peer BMI on the community level equals 16.61. The average BMI of males and females in 2004 was 16.32 and 16.28, respectively, but by 2009, these levels had increased for both males and females to 16.75 and 16.77, respectively. As regards self-reported perceptions of weight status, $11.34 \%$ of those sampled perceive themselves as overweight, as do $11.43 \%$ of the females and $11.27 \%$ of the males.

\section{Peer effect estimates}

Results for the entire sample and all subsamples (urban/rural, males/females, and children/adolescents) are reported in Table 2 . The results in column 1, with only the 
mean peer BMI controlled for, indicate that the average peer BMI significantly and positively correlates with individual BMI (a coefficient equal to 0.596). In column 2, when we introduce individual, mother, and household controls, the peer effect remains significant and positive but with a substantially decreased magnitude (a coefficient equal to 0.369). In column 3, with the addition of year and provincial dummies, as well as community characteristics, the peer coefficient remains significant but the magnitude declines even more (a coefficient equal to 0.281).

Columns 4-7 report the results for the subsamples: the urban and rural estimates indicate that peer effects are positively associated with individual BMI, yet the effect is somewhat stronger in rural than in urban areas $(0.283$ versus 0.131$)$. This finding may reflect the fact that in China, social ties and norms are stronger in rural communities than in urban areas (Peng, 2004). ${ }^{12}$ The middle and bottom of Table 2 report the estimates for the 3-9 (children) and 10-18 (adolescents) age groups, respectively. A comparison of the estimates in column 3 reveals that the peer effect is not as pronounced among children compared with adolescents. ${ }^{13}$ As in other studies (see, e.g., Trogdon et al., 2008), our estimates based on gender (see columns 6 and 7) show that peer effects are substantially stronger among females than males, especially among adolescents. ${ }^{14}$

12 Results for other variables included in the regressions but not reported indicate that respondent age is consistently and significantly positively related to individual BMI. Individuals with higher mothers' BMI are more likely to have a higher BMI. Interestingly, those whose mothers have a higher education level also tend to have a higher BMI level. We also ran the regressions controlling for the average age of peers and find that results are quantitatively similar to our results in Table 2.

13 The study of Maximova et al. (2008) suggests that children and adolescents who are exposed to overweight parents and schoolmates are prone to underreport their bodyweight, and that younger children aged 9 are notoriously sensitive to the exposure to overweight/obesity both at home and in school.

14 In order to identify a causal relationship between peer effects and individual BMI, we also perform a two-stage Generalized Method of Moment (GMM) procedure. Following Trogdon et al. (2008) and Loh and Li (2013), we adopt average peers' parental BMI as instruments and our results indicate that average peer effects are positive $(0.355)$ and significant at the $5 \%$ level. We do, however, observe heteroskedasticity (Breusch-Pagan test $=84.81, p$-value $=0.00$ ). The results are not reported here, but are available upon request. As emphasized by Halliday and Kwak (2009), such an instrumental approach based on background information of peers might be problematic primarily because it comes at the high expense of increased measurement error and weaker instruments. 
Table 2 OLS estimates of peer effects on individual BMI (3- to 18-year-olds)

\begin{tabular}{|c|c|c|c|c|c|c|c|}
\hline & $\begin{array}{l}\text { (1) } \\
\text { All }\end{array}$ & $\begin{array}{l}\text { (2) } \\
\text { All }\end{array}$ & $\begin{array}{l}\text { (3) } \\
\text { All }\end{array}$ & $\begin{array}{c}(4) \\
\text { Urban }\end{array}$ & $\begin{array}{c}(5) \\
\text { Rural }\end{array}$ & $\begin{array}{c}\text { (6) } \\
\text { Male }\end{array}$ & $\begin{array}{c}(7) \\
\text { Female }\end{array}$ \\
\hline Average peer & $0.596^{* * *}$ & $0.369^{* * *}$ & $0.281^{* * *}$ & $0.131^{*}$ & $0.283^{* * *}$ & $0.166^{* * *}$ & $0.392^{* * *}$ \\
\hline BMI & $(0.033)$ & $(0.039)$ & $(0.042)$ & $(0.079)$ & $(0.051)$ & $(0.052)$ & $(0.065)$ \\
\hline $\mathrm{CI}$ & {$[0.532,0.659]$} & {$[0.293,0.445]$} & {$[0.199,0.364]$} & {$[-0.024,0.286]$} & {$[0.184,0.383]$} & {$[0.064,0.269]$} & {$[0.264,0.520]$} \\
\hline$N$ & 2186 & 2186 & 2186 & 528 & 1658 & 1191 & 995 \\
\hline $\operatorname{Adj} . R^{2}$ & 0.168 & 0.241 & 0.246 & 0.240 & 0.240 & 0.266 & 0.237 \\
\hline \multicolumn{8}{|c|}{ Children: 3-9-year olds } \\
\hline Average peer & $0.443^{* * *}$ & $0.367^{* * *}$ & $0.266^{* * *}$ & $\begin{array}{c}0.097 \\
(0.147)\end{array}$ & $\begin{array}{l}0.259^{* * *} \\
(0073)\end{array}$ & $\begin{array}{l}0.153^{* *} \\
(0.077)\end{array}$ & $\begin{array}{l}0.390^{* * *} \\
(0.100)\end{array}$ \\
\hline CI & {$[0.335,0.551]$} & {$[0.257,0.476]$} & {$[0.142,0.389]$} & {$[-0.192,0.385]$} & {$[0.115,0.403]$} & {$[0.002,0.304]$} & {$[0.193,0.587]$} \\
\hline$N$ & 1237 & 1237 & 1237 & 303 & 934 & 685 & 552 \\
\hline Adj. $R^{2}$ & 0.080 & 0.128 & 0.136 & 0.158 & 0.127 & 0.128 & 0.149 \\
\hline \multicolumn{8}{|c|}{ Adolescents: 10-18-year olds } \\
\hline $\begin{array}{l}\text { Average peer } \\
\text { BMI }\end{array}$ & $\begin{array}{l}0.521^{* * *} \\
(0.047)\end{array}$ & $\begin{array}{c}0.275^{* * *} \\
(0.056)\end{array}$ & $\begin{array}{l}0.132^{* *} \\
(0.061)\end{array}$ & $\begin{array}{l}-0.245^{*} \\
(0.139)\end{array}$ & $\begin{array}{c}0.138^{*} \\
(0.073)\end{array}$ & $\begin{array}{c}0.039 \\
(0.087)\end{array}$ & $\begin{array}{l}0.214^{* *} \\
(0.086)\end{array}$ \\
\hline CI & {$[0.429,0.613]$} & {$[0.164,0.385]$} & {$[0.013,0.251]$} & {$[-0.519,0.028]$} & {$[-0.005,0.281]$} & {$[-0.132,0.210]$} & {$[0.044,0.383]$} \\
\hline$N$ & 949 & 949 & 949 & 225 & 724 & 506 & 443 \\
\hline Adj. $R^{2}$ & 0.125 & 0.213 & 0.226 & 0.150 & 0.239 & 0.239 & 0.240 \\
\hline
\end{tabular}

Note: (1) just includes average BMI of peers, (2) includes individual characteristics (age and gender), mother characteristics (mother BMI, education and employment status), and household characteristics (household per capita income, household size) and also urban dummies. (3) includes controls as (2) but adding dummies of years (2004 as the base year) and provinces (Liaoning as the base province), dummies of public schools, dummy of fast food restaurants and recreational facilities in the community, 20 different food prices (yuan/kilograms, inflated to 2011) in the free market. (6) and (7) are controlled without gender dummy. CI means 95\% confidence intervals. Robust standard errors are in parentheses; ${ }^{*} p<0.1,{ }^{* *} p<0.05,{ }^{* * *} p<0.01$.

To check the heterogeneous response of peer effects on different points of the BMI distribution, we also estimate quantile regressions. As Table 3 shows, average peer BMI is significantly positive in both the children and adolescent samples on all points of the BMI distribution. Individuals in the upper part of the distribution (75th percentile), however, are more sensitive to average peer BMI than those at the 25th percentile (0.399 versus 0.207). ${ }^{15}$ Interestingly, the peer effects for females at the upper end of the distribution are stronger than those for males.

15 We also ran unconditional quantile regressions and obtained quite similar results as in Table 3. 
Table 3 Quantile regressions of peer effects on individual BMI (3- to 18-year-olds)

\begin{tabular}{lccc}
\hline All & $25 \%$ & $50 \%$ & $75 \%$ \\
\hline Average peer BMI & $0.207^{* * * *}$ & $0.308^{* * * * *}$ & $0.399^{* * * *}$ \\
& $(0.037)$ & $(0.045)$ & $(0.065)$ \\
\hline CI & {$[0.134,0.281]$} & {$[0.218,0.397]$} & {$[0.271,0.527]$} \\
$N$ & 2186 & 2186 & 2186 \\
Pseudo $R^{2}$ & 0.138 & 0.177 & 0.204 \\
\hline Males & $25 \%$ & $50 \%$ & $75 \%$ \\
\hline Average peer BMI & $0.246^{* * *}$ & $0.301^{* * * *}$ & $0.325^{* * *}$ \\
& $(0.052)$ & $(0.060)$ & $(0.097)$ \\
\hline CI & {$[0.145,0.348]$} & {$[0.184,0.418]$} & {$[0.135,0.515]$} \\
$N$ & 1191 & 1191 & 1191 \\
Pseudo $R^{2}$ & 0.155 & 0.188 & 0.219 \\
\hline Females & $25 \%$ & $50 \%$ & $75 \%$ \\
\hline Average peer BMI & $0.245^{* * *}$ & $0.299^{* * * *}$ & $0.433^{* * *}$ \\
& $(0.060)$ & $(0.075)$ & $(0.096)$ \\
\hline CI & {$[0.126,0.363]$} & {$[0.152,0.447]$} & {$[0.245,0.622]$} \\
$N$ & 995 & 995 & 995 \\
Pseudo $R^{2}$ & 0.147 & 0.195 & 0.212 \\
\hline
\end{tabular}

Note: Models include individual characteristics (age and gender), mother characteristics (mother BMI, education and employment status), and household characteristics (household per capita income, household size), urban dummies, dummies of years (2004 as the base year) and provinces (Liaoning as the base province), dummies of public schools, dummy of fast food restaurants and recreational facilities in the community, 20 different food prices (yuan/kilograms, inflated to 2011) in the free market. Split estimates are without gender dummies. CI means $95 \%$ confidence intervals. Bootstrapped standard errors are in parentheses; ${ }^{*} p<0.1,{ }^{* *} p<0.05,{ }^{* * *} p<0.01$.

In Table 4, we also estimate peer effects separately for children and adolescents. As the first panel shows, peer effects are significantly positive across the entire BMI distribution. However, girls in the upper part of the BMI distribution are particularly affected by peers $(0.577)$, with a peer effect for females at the 75th percentile over three times larger than that at the 25th percentile. 
Table 4 Quantile regressions of peer effects on childhood BMI (3- to 9-year-olds)

\begin{tabular}{lccc}
\hline All & $25 \%$ & $50 \%$ & $75 \%$ \\
\hline Average peer BMI & $0.160^{* * * * *}$ & $0.214^{* * * *}$ & $0.321^{* * * *}$ \\
& $(0.042)$ & $(0.052)$ & $(0.103)$ \\
\hline CI & {$[0.078,0.242]$} & {$[0.111,0.316]$} & {$[0.118,0.523]$} \\
$N$ & 1237 & 1237 & 1237 \\
Pseudo $R^{2}$ & 0.100 & 0.115 & 0.139 \\
\hline Males & $25 \%$ & $50 \%$ & $75 \%$ \\
\hline Average peer BMI & $0.155^{* *}$ & $0.244^{* * *}$ & 0.162 \\
& $(0.064)$ & $(0.079)$ & $(0.112)$ \\
\hline CI & {$[0.029,0.281]$} & {$[0.089,0.398]$} & {$[-0.058,0.383]$} \\
$N$ & 685 & 685 & 685 \\
Pseudo $R^{2}$ & 0.128 & 0.125 & 0.149 \\
\hline Females & $25 \%$ & $50 \%$ & $75 \%$ \\
\hline Average peer BMI & $0.182^{* * *}$ & $0.205^{* *}$ & $0.577^{* * *}$ \\
& $(0.091)$ & $(0.103)$ & $(0.165)$ \\
\hline CI & {$[0.002,0.362]$} & {$[0.002,0.409]$} & {$[0.253,0.901]$} \\
$N$ & 552 & 552 & 552 \\
Pseudo $R^{2}$ & 0.104 & 0.135 & 0.177 \\
\hline
\end{tabular}

Note: The estimated samples are restricted to the age group 3-9 years. Controls include individual characteristics (age and gender), mother characteristics (mother BMI, education and employment status), and household characteristics (household per capita income, household size), urban dummies, dummies of years (2004 as the base year) and provinces (Liaoning as the base province), dummies of public schools, dummy of fast food restaurants and recreational facilities in the community, 20 different food prices (yuan/kilograms, inflated to 2011) in the free market. Split estimates are without gender dummies. CI means 95\% confidence intervals. Bootstrapped standard errors are in parentheses; ${ }^{*} p<0.1, \stackrel{* *}{p}<<0.05, \stackrel{* * *}{p}<0.01$.

With regard to adolescents aged 10-18 (see Table 5), only adolescents at the upper end of the distribution have a significant positive effect, a marked contrast from the quantile results for children and the general finding that peer effects among children are larger. 
Table 5 Quantile regressions of peer effects on adolescent BMI (10- to 18-year-olds)

\begin{tabular}{lccc}
\hline All & $25 \%$ & $50 \%$ & $75 \%$ \\
\hline Average peer BMI & 0.086 & 0.103 & 0.240 \\
& $(0.061)$ & $(0.076)$ & $(0.096)$ \\
\hline CI & {$[-0.034,0.207]$} & {$[-0.047,0.253]$} & {$[0.051,0.429]$} \\
$N$ & 949 & 949 & 949 \\
Pseudo $R^{2}$ & 0.162 & 0.189 & 0.205 \\
\hline Males & $25 \%$ & $50 \%$ & $75 \%$ \\
\hline Average peer BMI & 0.013 & 0.079 & 0.217 \\
& $(0.094)$ & $(0.109)$ & $(0.152)$ \\
\hline CI & {$[-0.171,0.198]$} & {$[-0.134,0.293]$} & {$[-0.081,0.515]$} \\
$N$ & 506 & 506 & 506 \\
Pseudo $R^{2}$ & 0.195 & 0.220 & 0.245 \\
\hline Females & $25 \%$ & $50 \%$ & $75 \%$ \\
\hline Average peer BMI & 0.128 & 0.106 & 0.219 \\
& $(0.112)$ & $(0.110)$ & $(0.138)$ \\
\hline CI & {$[-0.092,0.348]$} & {$[-0.111,0.323]$} & {$[-0.053,0.490]$} \\
$N$ & 443 & 443 & 443 \\
Pseudo $R^{2}$ & 0.206 & 0.229 & 0.234 \\
\hline
\end{tabular}

Note: The estimated samples are restricted to age groups of 10-18 years old. Controls include individual characteristics (age and gender), mother characteristics (mother BMI, education and employment status), and household characteristics (household per capita income, household size), urban dummies, dummies of years (2004 as the base year) and provinces (Liaoning as the base province), dummies of public schools, dummy of fast food restaurants and recreational facilities in the community, 20 different food prices (yuan/kilograms, inflated to 2011) in the free market. Split estimates are without gender dummies. CI means $95 \%$ confidence intervals. Bootstrapped standard errors are in parentheses; ${ }^{*} p<0.1,{ }^{* *} p<0.05, \stackrel{* * *}{p} p<0.01$.

Because some unobserved or omitted factors may still exist, we also estimate a fixed effects model. As Table 6 shows, although the average peer BMI is still significantly and positively correlated with individual BMI, the coefficient is substantially smaller than in the OLS model ( 0.17 vs. 0.28$)$. This result is similar to that observed in Asirvatham et al. (2013a), confirming the importance of controlling for unobserved time-invariant fixed effects. Interestingly, the coefficient of a random effects estimate is 0.27 , which is quite similar to that of the OLS estimate.

Table 6 Fixed-effects estimates of peer effects on individual BMI (3- to 18-year-olds)

\begin{tabular}{lcc}
\hline Variables & FE & RE \\
\hline Average peer BMI & $0.169^{* * *}$ & $0.270^{* * *}$ \\
& $(0.046)$ & $(0.036)$ \\
CI & {$[0.078,0.259]$} & {$[0.200,0.340]$} \\
\hline Control for food prices & Yes & Yes \\
Observations & 1772 & 1772 \\
$R^{2}$ & 0.214 & - \\
\hline
\end{tabular}

Note: The dependent variable is individual BMI. All samples are restricted to the 2004, 2006, and 2009 waves. Model (1) is a fixed-effects estimate with group dummies (group 1=2004 and 2006, group 2=2004 and 2009, and group 3=2006 and 2009, with group 3 as the reference group). CI =95\% confidence intervals; standard errors are in parentheses; ${ }^{*} p<0.1,{ }^{* *} p<0.05,{ }^{* * *} p<0.01$. 


\section{Operation of peer effects}

To explore the pathways through which peer effects may operate, we use an ordered probit to analyze adolescent's self-reported weight perceptions (see Table 7). Despite expectations that once individual BMI and other variables are controlled for, a larger average peer BMI might reduce the probability of considering oneself overweight, this result is only significant at the $10 \%$ level and only for females. ${ }^{16}$ This observation may imply that norms of bodyweight for females do in fact change with peers' BMI levels. $^{17}$

Table 7 Marginal effects of ordered probit estimates of peer effects on adolescents' self-reported weight status (10-to 18-year-olds)

\begin{tabular}{lccc}
\hline Variables & All & Males & Females \\
\hline Self-reported underweight & 0.004 & -0.011 & $0.017^{*}$ \\
& $(0.007)$ & $(0.010)$ & $(0.009)$ \\
CI & {$[-0.009,0.017]$} & {$[-0.030,0.009]$} & {$[-0.0001,0.034]$} \\
Self-reported normal weight & -0.001 & 0.005 & -0.006 \\
& $(0.003)$ & $(0.005)$ & $(0.004)$ \\
CI & {$[-0.006,0.004]$} & {$[-0.004,0.014]$} & {$[-0.015,0.002]$} \\
Self-reported overweight & -0.002 & 0.006 & $-0.011^{*}$ \\
& $(0.004)$ & $(0.005)$ & $(0.006)$ \\
CI & {$[-0.010,0.001]$} & {$[-0.005,0.016]$} & {$[-0.022,0.0004]$} \\
\hline$N$ & 776 & 426 & 350 \\
Pseudo $R^{2}$ & 0.157 & 0.204 & 0.226 \\
\hline
\end{tabular}

Note: Controls include individual characteristics (age and gender), mother characteristics (mother BMI, education and employment status), and household characteristics (household per capita income, household size), urban dummies, dummies of years (2004 as the base year) and provinces (Liaoning as the base province), dummies of public schools, dummy of fast food restaurants and recreational facilities in the community, 20 different food prices (yuan/kilograms, inflated to 2011) in the free market. Split estimates are without gender dummies. CI means 95\% confidence intervals. Standard errors are in parentheses; ${ }^{*} p<0.1,{ }^{* *} p<0.05,{ }^{* * *} p<0.01$.

We also recoded the self-reported perceptions of weight into a binary variable ( 1 =overweight, $0=$ normal or underweight) and then estimated a probit model. As Baum (2006) emphasizes, it is particularly useful to examine the distribution of the marginal effects based on each individual in the sample. We thus report the marginal

16 Xie et al. (2003) indicates that female adolescents are more likely to report being overweight. Furthermore, relatively higher perceived peer isolation (defined on a 4-point scale, whether respondents have experienced being looked down or insulted or attacked or isolated by classmates) can be identified among female adolescents who reported being overweight compared with underweight and normal weight.

17 We also followed Blanchflower et al. (2009) by introducing a measure of relative BMI into the specification. The results, available upon request, are qualitatively very similar. 
effects for different ages and separately for males and females (see Figure A1-A3 in Appendix A). According to these calculations, in the full sample, the effects are negative and increase with age (see Figure A1). Likewise, marginal effects for females are consistently negative and rise with age (see Figure A2). In stark contrast, marginal effects for males are uniformly positive but decrease with age. For 10-yearolds, they are less than 0.007 and for 17-year-olds, approximately 0.001 (see Figure A3). These results appear to imply that predicted probabilities of self-reported overweight increase as the age of the adolescent increases, particularly for females. Such is not the case for males.

In general, our results are in line with the assumption that peer BMI could influence individual bodyweight perceptions; however, the significance is low. Although this latter could be associated with the low sample size, alternatively it could signal that changes in community-level BMI need not necessarily change perceptions. Rather, they may influence the acceptability of being overweight; that is, even when individuals know they are overweight, the social pressure to lose weight may be lower when community BMI levels are high.

\section{Existence of nonlinear peer effects: parametric estimates}

Next, to determine whether community peer effects exert a nonlinear effect on individual BMI for children versus adolescents, we introduce parametric estimates of peer BMI using a squared term of average peer BMI. The OLS estimates (see Table 8) reveal that the average peer BMI (positive) and its squared term (negative) are significant for the full sample and adolescents, but not for children. Specifically, they suggest a possible concave relation between peer effects and individual body weight for the full sample and adolescents, which levels out at relatively high BMI levels (around 24 and 20, respectively). 
Table 8 Parametric estimates of nonlinear peer effects on individual BMI (3- to 18-year- olds)

\begin{tabular}{lccc}
\hline Variables & $\begin{array}{c}\text { Full sample } \\
(3-18 \text { year })\end{array}$ & $\begin{array}{c}\text { Children } \\
(3-9 \text { years })\end{array}$ & $\begin{array}{c}\text { Adolescents } \\
(10-18 \text { years })\end{array}$ \\
\hline Average peer BMI & $1.057^{* *}$ & 0.531 & $1.813^{* *}$ \\
& $(0.432)$ & $(0.682)$ & $(0.709)$ \\
CI & {$[0.210,1.904]$} & {$[-0.806,1.868]$} & {$[0.422,3.204]$} \\
Average peer BMI squared & $-0.022^{*}$ & -0.008 & $-0.046^{* *}$ \\
& $(0.012)$ & $(0.020)$ & $(0.020)$ \\
CI & {$[-0.046,0.002]$} & {$[-0.048,0.032]$} & {$[-0.085,-0.007]$} \\
\hline$N$ & 2186 & 1237 & 949 \\
Adj. $R^{2}$ & 0.247 & 0.135 & 0.231 \\
\hline
\end{tabular}

Note: The dependent variable is individual BMI. Controls include individual characteristics (age and gender), mother characteristics (mother's BMI, education, and employment status), and household characteristics (household per capita income, household size), as well as an urban dummy, year dummies (with 2004 as the base year) and province dummies (with Liaoning as the base province), and dummies for public schools, fast food restaurants and recreational facilities in the community, and 20 different free market food prices (yuan/kilograms, inflated to 2011). CI $=95 \%$ confidence intervals, shown in brackets; robust standard errors are in parentheses; ${ }^{*} p<0.1,{ }^{* *} p<0.05,{ }^{* * *} p<0.01$.

Following Trogdon et al. (2008), we also estimate a double-log model, with the coefficient of average peer BMI now representing elasticity. Like the results in Table 1, the elasticities are consistently positive and significant. Once individual, household, and community factors are controlled for, the elasticity of peer effects is 0.281 (see Table A2, column 3). The quantile results also indicate that the elasticities of peer effects increase as the percentiles of individual BMI rise $(25$ th $=0.23,50$ th $=0.31$, and 75th=0.36, see Table A3, panel 1). ${ }^{18}$

\section{Robustness check using another peer group}

Following Loh and Li (2013), we employ an additional peer reference group that might capture information on peer networks at the school level; namely, those in the same age band but also at the same school and community level. ${ }^{19}$ We find a significant correlation between peer effects and individual bodyweight except for

18 To identify whether peer effects have a nonlinear effect, we also estimated a semiparametric partially linear model (PLM), using Robinson's (1988) double residual method. The results are graphed in Figure A4 in the appendix. In general, we note a positive linear relation between peer BMI levels and individual BMI for average peer BMI levels ranging between 14 and 19. To further assess whether the nonparametric functions of peer effects might be approximated by some parametric polynomial form, we employ Hardle and Mammen's (1993) specification test. Based on the PLM model, the results (available upon request) indicate that the null hypothesis (i.e., a parametric polynomial of degree 1) cannot be rejected, suggesting that the relation between individual BMI and average peer BMI is indeed linear.

19 Our sample size is restricted to respondents aged 6 to 18. Specifically, the school age bands are 6-8, 9-11, 1214, and 15-17 years. As mentioned previously, we also use a leave-out average peer definition. 
males (positive but insignificant, see Table A4), with the magnitude of peer influence for females being much stronger than that for males. Quantile regressions, run as an additional step, demonstrate that peer effects are again more evident for those in the upper distribution of individual BMI (25th $=0.12$, 50 th $=0.26$, and 75 th $=0.33$, see Table A5).

Robustness check for strength of same-gender peer effects

To follow up on the discussion in Christakis and Fowler (2007), we also examine whether same-gender peers have a relatively greater influence on individual bodyweight. ${ }^{20}$ We find that same-gender peer effects are not stronger than mixedgender peer effects in all prior results except for the full sample of individuals aged 318 and children aged 3-9 (see Tables 2 and A6). Additional results based on quantile regressions, however, lend scant support for the effects of same-gender peers on individual bodyweight being stronger than those of mixed-gender peers except for individuals aged 3-18 at the 50th percentile (see Tables 3 and A7). On the other hand, females at the 75th percentile, in contrast to males, are more responsive to samegender peer effects.

\section{Robustness check comparing results with BMI z-score}

To check the robustness of the results, we use BMI z-scores based on the IOTF growth charts. The corresponding OLS estimates show that peer effects are present and the magnitudes are quantitatively similar to previous estimates using individual BMI (except for the urban group, see Table A8). Quantile regressions also confirm that peer effects are much stronger at the upper end of the BMI distribution, particularly among females (see Table A9).

\section{Robustness check using waist circumference}

The use of BMI as a proxy for body fat has come under criticism lately because of its inability to distinguish fat from muscle, bone, and other lean body mass (Yusuf et al., 2005; Gallagher et al., 1996; Wellens et al., 1996; McCarthy et al., 2006; Romero-

\footnotetext{
20 Not only do several U.S. studies suggest that adolescents are more sensitive to the bodyweight of same-gender peers (see, e.g., Renna et al., 2008), but Loh and Li (2013) also find that same-gender peer effects for female adolescents are stronger than those for male adolescents in rural China.
} 
Corral et al., 2006; Burkhauser and Cawley, 2008). We therefore also estimate our models replacing BMI with waist circumference, which is arguably the most reliable field method for measuring abdominal visceral fat (Snijder et al., 2003). In these results, reported in Tables A10 and A11, the following points are worth noting: although the peer effect is identifiable using this measure, in our sample, the significance levels are substantially lower, especially for children. These findings are in line with those of Burkhauser and Cawley (2008), who show that different measures of obesity correlate differently with certain social science outcomes. Hence, an interesting avenue for future research would be to assess peer effects using different obesity measures. ${ }^{21}$

\section{Conclusions}

This analysis of obesity-related peer effects outside the Western world, which uses CHNS data to analyze obesity-related peer effects among aged 3- to 18-year-old Chinese, documents the following important observations: First, peer effects do indeed exist, not only among adolescents but also younger children. This finding highlights the importance of peers forming health lifestyles - including diets - at a young age. Second, the magnitude of the peer effects varies substantially along the individual BMI distribution, being stronger at the upper end than at the bottom or median, which suggests that individuals with a higher BMI are more likely to be affected by peer influence. Third, and in line with U.S. studies on adolescents (e.g., Trogdon et al., 2008), females are generally more affected than males. Peer effects are also substantially larger in rural than in urban areas. Finally, our test of the hypothesis that broad community-level peer measures (possibly via changing societal norms) are related to adolescent's self-perceived bodyweight provides evidence that a higher average peer group BMI is negatively correlated with the probability of a selfperception of overweight, especially for adolescent girls.

Some caveats should be mentioned: First, the surveyed sample of the CHNS is not a representative for China. However, those selected provinces are regionally

\footnotetext{
${ }^{21}$ Following Mora and Gil (2013), we conducted a falsification test that replaces BMI with height, which is unlikely to be affected by peers. The results show that average peers' BMI has no impacts on individual height.
} 
representative. Second, we cannot rule out correlated effects even though controlling for a wealth of household and community characteristics. This could lead to an upward bias. Our analysis on the pathways through which peer effects operate cannot either claim to be causal, yet is supportive of the notion that peers may influence perceptions.

Overall, therefore, our results not only support the notion that peer effects exist among children and adolescents in both urban and rural China but that their magnitude (OLS: 0.13 and FE: 0.17) falls within the general range found for adolescents in the U.S. ${ }^{22}$ (0.16 to 0.30$)$ using specifications similar to ours. Hence, living in a collectivistic society like China's does not, prima facie, appear to make a large difference in the magnitude of peer effects. Evaluating to what extent such a conclusion is generalizable, however, would require much more research across the globe.

\section{Acknowledgments}

This research uses data from the China Health and Nutrition Survey (CHNS). We thank the National Institute of Nutrition and Food Safety, China Center for Disease Control and Prevention; the Carolina Population Center, University of North Carolina at Chapel Hill; the National Institutes of Health (NIH; R01-HD30880, DK056350, and R01-HD38700); and the Fogarty International Center, NIH, for financial support for the CHNS data collection and analysis files since 1989. We thank those parties, the China-Japan Friendship Hospital, and the Ministry of Health for support for the CHNS 2009 survey. The study is an output of a scholarship from the Food Security Center at the University of Hohenheim, which is part of the DAAD (German Academic Exchange Service) program "Exceed” and is supported by DAAD and the German Federal Ministry for Economic Cooperation and Development (BMZ). This paper was presented at the 28th Annual Conference of the European Society for Population Economics in Braga, the 13th Annual International Conference on Health

\footnotetext{
22 Renna et al. (2008), using OLS estimates, show the magnitudes of peer effects to be around 0.164 and 0.165 for males and females, respectively. They do not, however, report their results for the full sample. Trogdon et al. (2008), however, also using OLS estimates, identify a peer effect magnitude of 0.30 for the full sample, while Halliday and Kwak (2009), using fixed effects, estimate it at 0.19 .
} 
Economics, Management \& Policy in Athens, the 2014 Seminar of CINCH Academy

- The Essen Summer School in Health Economics in Essen, the 2014 Seminar of The DEFAP-LASER Summer School in Applied Microeconometrics in Milan and the 2014 Seminar on Health Care \& Public Management in Stuttgart. We would like to thank the participants for valuable comments as well as Wencke Gwozdz, Wei Huang and Peter Zweifel for valuable comments on an earlier version of this paper.

\section{References}

Ali, M.M., Amialchuk, A., Gao, S., and Heiland, F. (2012), "Adolescent weight gain and social networks: Is there a contagion effects?” Applied Economics, 44(23): 2989-2983.

An, W.H. (2011), “Models and methods to identify peer effects”, Sage Handbook of Social Network Analysis, ed. by John Scott and Peter J. Carrington, Sage Publications, London.

Angrist, J. (2013), “The perils of peer effects”, NBER Working Paper No. 19774. Available at $<$ http://www.nber.org/papers/w19774>

Asirvatham, J., Nayga, Jr., R.M., and Thomsen, M.R. (2013a), "Peer-effects on child obesity", Paper presented at the Agricultural \& Applied Economics Association's 2013 AAEA \& CAES Joint Annual Meeting Washington, DC, August 4-6, 2013.

Asirvatham, J., Nayga, Jr., R.M., and Thomsen, M.R. (2013b), "Peer-effects in obesity among public elementary school children: a grade-level analysis", working paper, Department of Agricultural Economics and Agribusiness, University of Arkansas, Fayetteville.

Baum, C.F. (2006), “An introduction to modern econometrics using Stata”, Stata Press, Texas.

Blanchflower, D.G., Landeghem, B., and Oswald, A.J. (2009), "Imitative obesity and relative utility”, Journal of the European Economic Association, 7(2-3): 528-538.

Burke, M.A., and Heiland, F. (2007), “Social dynamics of obesity”, Economic Inquiry, 45(3): 571591.

Burkhauser, R.V., and Cawley, J. (2008), "Beyond BMI: The value of more accurate measures of fatness and obesity in social science research”, Journal of Health Economics, 27(2): 519-529.

Carman, K.G., and Zhang, L. (2012), "Classroom peer effects and academic achievement: Evidence from a Chinese middle school”, China Economic Review, 23(2): 223-237.

Chen, Z., and Meltzer, D. (2008), "Beefing up with the Chans: Evidence for the effects of relative income and income equality on health from the China Health and Nutrition Survey", Social Science \& Medicine, 66(11): 2206-2217.

Chen, Z., Jiang, S.Q., Lu, M., and Sato, H. (2008), "How do heterogeneous social interactions affect the peer effect in rural-urban migration? Empirical evidence from China", Hitotsubashi University, Global COE Hi-Stat Discussion Paper No. 008.

Cheng, T.O. (2012), “Childhood obesity in modern China”, International Journal of Cardiology, 157(3):315-317. 
China Daily, (2008), “Childhood obesity a heavy burden for parents". Available at $<$ http://www.chinadaily.com.cn/china/2008-12/03/content_7265415.htm>

Christakis, N.A., and Fowler, J.H. (2007), "The spread of obesity in a large social network over 32 years”, New England Journal of Medicine, 357: 370-379.

Cohen-Cole, E., and Fletcher, J.M. (2008), "Is obesity contagious? Social networks vs. environmental factors in the obesity epidemic”, Journal of Health Economics, 27(5): 1382-1387.

Cole, T.J., Bellizzi, M.C., Flegal, K.M., and Dietz, W.H. (2000), "Establishing a standard definition for child overweight and obesity worldwide, international survey”, BMJ, 320(7244): 1240-1243.

de la Haye, K., Robins, G., Mohr, P., and Wilson, C. (2011), "Homophily and contagion as explanations for weight similarities among adolescent friends", Journal of Adolescent Health, 49(4): 421-427.

Ding, W.L., and Lehrer, S.F. (2007), “Do peers affect student achievement in China's secondary schools?” Review of Economics and Statistics, 89(2): 300-312.

Dishion, T.J., and Tipsord, J.M. (2011), "Peer contagion in child and adolescent social and emotional development”, Annual Review of Psychology, 62: 189-214.

Du, S.F., Mroz, T.A., Zhai, F.Y., and Popkin, B.M. (2004), "Rapid income growth adversely affects diet quality in China-particularly for the poor!” Social Science \& Medicine, 59(7): 15051515.

Fletcher, J.M. (2011), "Peer effects and obesity”, The Oxford Handbook of the Social Science of Obesity, ed. by John Cawley, Oxford University Press, New York.

Fowler, J.H., and Christakis, N.A. (2008), "Estimating peer effects on health in social networks: A response to Cohen-Cole and Fletcher; and Trogdon, Nonnemaker, and Pais", Journal of Health Economics, 27(5): 1400-1405.

Fung, H.D. (1999), "Becoming a moral child: The socialization of shame among young Chinese children”, Ethos, 27(2): 180-209.

Gallagher, D., Visser, M., Sepúlveda, D., Pierson, R.N., Harris, T., and Heymsfield, S.B. (1996), "How useful is body mass index for comparison of body fatness across age, sex, and ethnic groups?” American Journal of Epidemiology, 143(3): 228-239.

Gonzalez-Mena, J. (1993), "Multicultural issues in child care”, Mayfield Publishing, Mountain View, CA.

Guo, X.G., Mroz, T.A., Popkin, B.M., and Zhai, F.Y. (2000), "Structural change in the impact of income on food consumption in China, 1989-1993”, Economic Development and Cultural Change, 48(4): 737-760.

Halliday, T.J., and Kwak, S. (2009), "Weight gain in adolescents and their peers”, Economics and Human Biology, 7(2): 181-190.

Han, L., and Li, T. (2009), "The gender difference of peer influence in higher education", Economics of Education Review, 28(1): 129-134.

Hardle, W., and Mammen, E. (1993), "Comparing nonparametric versus parametric regression fits”, Annals of Statistics, 21(4): 1926-1947.

Kato, T., and Shu, P. (2009), "Peer effects, social networks, and intergroup competition in the workplace”, Aarhus School of Business, Department of Economics, Working Paper No. 09-12, University of Aarhus. 
Kelder, S.H., Perry, C.L., Klepp, K.I., and Lytle, L.L. (1994), "Longitudinal tracking of adolescent smoking, physical activity, and food choice behaviors", American Journal of Public Health, 84(7): 1121-1126.

Larson, N.I., Wall, M.M., Story, M.T., and Neumark-Sztainer, D.R. (2013), "Home/family, peer, school, and neighborhood correlates of obesity in adolescents”, Obesity, 21(9): 1858-1869.

Leatherdale, S., and Papadakis,S. (2011), "A multi-level examination of the association between older social models in the school environment and overweight and obesity among younger students”, Journal of Youth and Adolescence, 40(3): 361-372.

Li, Q., Zang, W.B., and An, L. (2013), "Peer effects and school dropout in rural China”, China Economic Review, 27: 238-248.

Liang, Y.J., Xi, B., Song, A.Q., Liu, J.X., and Mi, J. (2012), “Trends in general and abdominal obesity among Chinese children and adolescents 1993-2009”, Pediatric Obesity, 7(5): 355-364.

Loh, C.A., and Li, Q. (2013), "Peer effects in adolescent bodyweight: Evidence from rural China", Social Science \& Medicine, 86: 35-44.

Lu, M., and Wan, G.H. (2014), "Urbanization and urban systems in the People’ Republic of China: Research findings and policy recommendations”, Journal of Economic Surveys, 28(4): 671-685.

Manski, C.F. (1993), "Identification of endogenous social effects: The reflection problem", Review of Economic Studies, 60(3): 531-542.

McCarthy, H.D. (2006), "Body fat measurements in children as predictors for the metabolic syndrome: Focus on waist circumference”, Proceedings of the Nutrition Society, 65(4): 385-92.

Monasta, L., Batty, G.D., Cattaneo, A., Lutje, V., Ronfani, L., Van Lenthe, F.J., and Brug, J. (2010), "Early-life determinants of overweight and obesity: A review of systematic reviews", Obesity Reviews, 11(10): 695-708.

Mora, T., and Gil, J. (2013), "Peer effects in adolescent BMI: Evidence from Spain”, Health Economics, 22(5): 501-516.

Maximova, K., McGrath, J.J., Barnett, T., O'Loughlin, J., Paradis, G., and Lambert, M. (2008), "Do you see what I see? Weight status misperception and exposure to obesity among children and adolescents”, International Journal of Obesity, 32(6): 1008-1015.

Peng, Y.S. (2004), "Kinship networks and entrepreneurs in China's transitional economy", American Journal of Sociology, 109(5): 1045-1074.

Popkin, B.M., Du, S.F., Zhai, F.Y., and Zhang, B. (2011), “Cohort profile: The China Health and Nutrition Survey - monitoring and understanding socio-economic and health change in China, 1989-2011”, International Journal of Epidemiology, 39(6): 1435-1440.

Renna, F. Grafova, I.B., and Thakur, N. (2008), "The effect of friends on adolescent body weight", Economics and Human Biology, 6(3): 377-387.

Robinson, P.M. (1988), “Robinson-N-consistent semiparametric regression”, Econometrica, 56(4): 931-954.

Romero-Corral, A., Montori, V.M., Somers, V.K., Korinek, J., Thomas, R.J., Allison, T.G., Mookadam, F., and Lopez-Jimenez, F. (2006), "Association of bodyweight with total mortality and with cardiovascular events in coronary artery disease: A systematic review of cohort studies”, Lancet, 368(9536): 666-678. 
Schwartz, D.L., Chase, C.C., Oppezzo, M.A., and Chin, D.B. (2011), "Practicing versus inventing with contrasting cases: The effects of telling first on learning and transfer", Journal of Educational Psychology, 103(4): 759-775.

Shan, X.Y., Xi, B., Cheng, H., Hou, D.Q., Wang, Y.F., and Mi, J. (2010), "Prevalence and behavioral risk factors of overweight and obesity among children aged 2-18 in Beijing, China", International Journal of Pediatric Obesity, 5(5): 383-389.

Snijder, M.B., Dekker, J.M., Visser, M., Bouter, L.M., Stehouwer, C.D., Kostense, P.J., Yudkin J.S., Heine, R.J., Nijpels, G., and Seidell, J.C. (2003), "Associations of hip and thigh circumferences independent of waist circumference with the incidence of type 2 diabetes: The Hoorn Study”, American Journal of Clinical Nutrition, 77(5): 1192-1197.

Trogdon, J.G., Nonnemaker, J., and Pais, J. (2008), "Peer effects in adolescent overweight", Journal of Health Economics, 27(5): 1388-1399.

Valente, T.W., Fujimoto, K., Chou, C.P., Spruijt-Metz, D. (2009), "Adolescent affiliations and adiposity: A social network analysis of friendships and obesity", Journal of Adolescent Health, 45(2): 202-204.

Verardi, V., and Debarsy, N. (2012), “Robinson's square root of N consistent semiparametric regression estimator in Stata”, Stata Journal, 12(4): 126-135.

Wellens, R.I., Roche, A.F., Khamis, H.J., Jackson, A.S., Pollock, M.L., and Siervogel, R.M. (1996), "Relationships between the Body Mass Index and body composition", Obesity Research, 4(1): 35-44.

Xie, B., Liu, C., Chou, C.P., Xia, J., Spruijt-Metz, D., Gong, J., Li, Y., Wang, H., and Johnson, C.A. (2003), "Weight perception and psychological factors in Chinese adolescents", Journal of Adolescent Health, 33(3): 202-210.

Yakusheva, O., Kapinos, K.A., and Weiss, M. (2011), "Peer effects and the freshman 15: Evidence from a natural experiment”, Economics and Human Biology, 9(2): 119-132.

Yakusheva, O., Kapinos, K.A., and Eisenberg, D. (2014), "Estimating heterogeneous and hierarchical peer effects on body weight using roommate assignments as a natural experiment", The Journal of Human Resources, 49(1): 234-261.

Yang, M.Z., and Huang, R. (2013), "Asymmetric association between exposure to obesity and weight gain among adolescents”, Eastern Economic Journal, 40(1): 96-118.

Yusuf, S., Hawken, S., Ounpuu, S., Bautista, L., Franzosi, M.G., Commerford, P., Lang, C.C., Rumboldt, Z., Onen, C.L., Li, L.S., Tanomsup, S., Wangai, P.Jr., Razak, F., Sharma, A.M., and Anand, S.S., on behalf of the INTERHEART study investigators (2005), "Obesity and the risk of myocardial infarction in 27,000 participants from 52 countries: A case-control study", Lancet, 366(9497): 1640-1649. 


\section{Appendix:}

Table A1: Descriptive statistics

\begin{tabular}{|c|c|c|c|c|c|}
\hline Variable & Obs. & Mean & Std. Dev. & Min. & Max. \\
\hline \multicolumn{6}{|l|}{ Dependent variable } \\
\hline BMI & 2186 & 16.61 & 2.77 & 10.79 & 30.48 \\
\hline Self-reported perception of weight & 776 & 0.93 & 0.54 & 0 & 2 \\
\hline BMI z-score (based on IOTF) & 2186 & -0.15 & 1.20 & -4.49 & 4.82 \\
\hline \multicolumn{6}{|l|}{ Independent variables } \\
\hline Average peer BMI & 2186 & 16.61 & 1.91 & 12.14 & 24.05 \\
\hline Age & 2186 & 9.13 & 3.28 & 3 & 17.77 \\
\hline Gender dummy & 2186 & 0.54 & 0.50 & 0 & 1 \\
\hline \multicolumn{6}{|l|}{ Family and mother variables } \\
\hline Mother’s BMI & 2186 & 22.61 & 3.09 & 15.57 & 36.53 \\
\hline Mother's education & 2186 & 8.26 & 3.81 & 0 & 21 \\
\hline Mother's employment status & 2186 & 0.76 & 0.43 & 0 & 1 \\
\hline Log(household income) & 2186 & 8.44 & 1.08 & 0.76 & 11.59 \\
\hline Household size & 2186 & 4.54 & 1.42 & 2 & 13 \\
\hline Urban dummy & 2186 & 0.24 & 0.43 & 0 & 1 \\
\hline \multicolumn{6}{|l|}{ Community variables } \\
\hline \multicolumn{6}{|l|}{ Public school dummies } \\
\hline Primary school & 2186 & 0.73 & 0.44 & 0 & 1 \\
\hline Low middle school & 2186 & 0.34 & 0.48 & 0 & 1 \\
\hline Upper middle school & 2186 & 0.15 & 0.36 & 0 & 1 \\
\hline \multicolumn{6}{|l|}{ Fast food restaurant dummy } \\
\hline Fast food restaurants & 2186 & 0.15 & 0.35 & 0 & 1 \\
\hline \multicolumn{6}{|l|}{ Recreation facilities dummies } \\
\hline Gym/exercise centers & 2186 & 0.12 & 0.33 & 0 & 1 \\
\hline Park/public recreation places & 2186 & 0.17 & 0.38 & 0 & 1 \\
\hline Playgrounds & 2186 & 0.32 & 0.47 & 0 & 1 \\
\hline \multicolumn{6}{|l|}{ Free market food price dummies } \\
\hline Rice & 2186 & 3.72 & 0.69 & 1.85 & 5.67 \\
\hline Bleached flour & 2186 & 4.03 & 1.15 & 1.43 & 7.78 \\
\hline Unbleached flour & 2186 & 3.50 & 0.90 & 1.19 & 7.73 \\
\hline Corn flour & 2186 & 3.80 & 1.59 & 1.41 & 10.31 \\
\hline Millet & 2186 & 5.99 & 2.14 & 2.24 & 12.88 \\
\hline Sorghum & 2186 & 4.55 & 2.31 & 0.55 & 12.93 \\
\hline Rapeseed oil & 2186 & 12.36 & 4.63 & 1.07 & 30.92 \\
\hline Soybean oil & 2186 & 11.22 & 3.01 & 4.68 & 21.29 \\
\hline Peanut oil & 2186 & 16.07 & 5.65 & 6.57 & 50.2 \\
\hline Sugar & 2186 & 6.11 & 1.32 & 3.09 & 11.39 \\
\hline Eggs & 2186 & 9.70 & 2.64 & 4.39 & 19.39 \\
\hline Vegetables & 2186 & 2.23 & 1.09 & 0.32 & 7.28 \\
\hline Pork & 2186 & 19.66 & 4.03 & 9.36 & 28.38 \\
\hline Chicken & 2186 & 19.81 & 8.28 & 6.67 & 49.53 \\
\hline Beef & 2186 & 31.05 & 10.38 & 9.37 & 68.23 \\
\hline Mutton & 2186 & 31.51 & 11.36 & 11.45 & 66.99 \\
\hline Fresh milk & 2186 & 2.44 & 1.28 & 0.51 & 12.82 \\
\hline Milk powder & 2186 & 45.27 & 19.98 & 10.44 & 134.48 \\
\hline Fish & 2186 & 12.10 & 3.92 & 1.64 & 27.64 \\
\hline Beancurd & 2186 & 3.35 & 1.13 & 1.07 & 9.28 \\
\hline
\end{tabular}


Source: China Health and Nutrition Survey 2004, 2006, and 2009. The age group is restricted to 3- to 18-year-olds. The BMI z-score is calculated based on IOTF criteria. Self-reported perception of weight is restricted to adolescents aged 10-17.99.

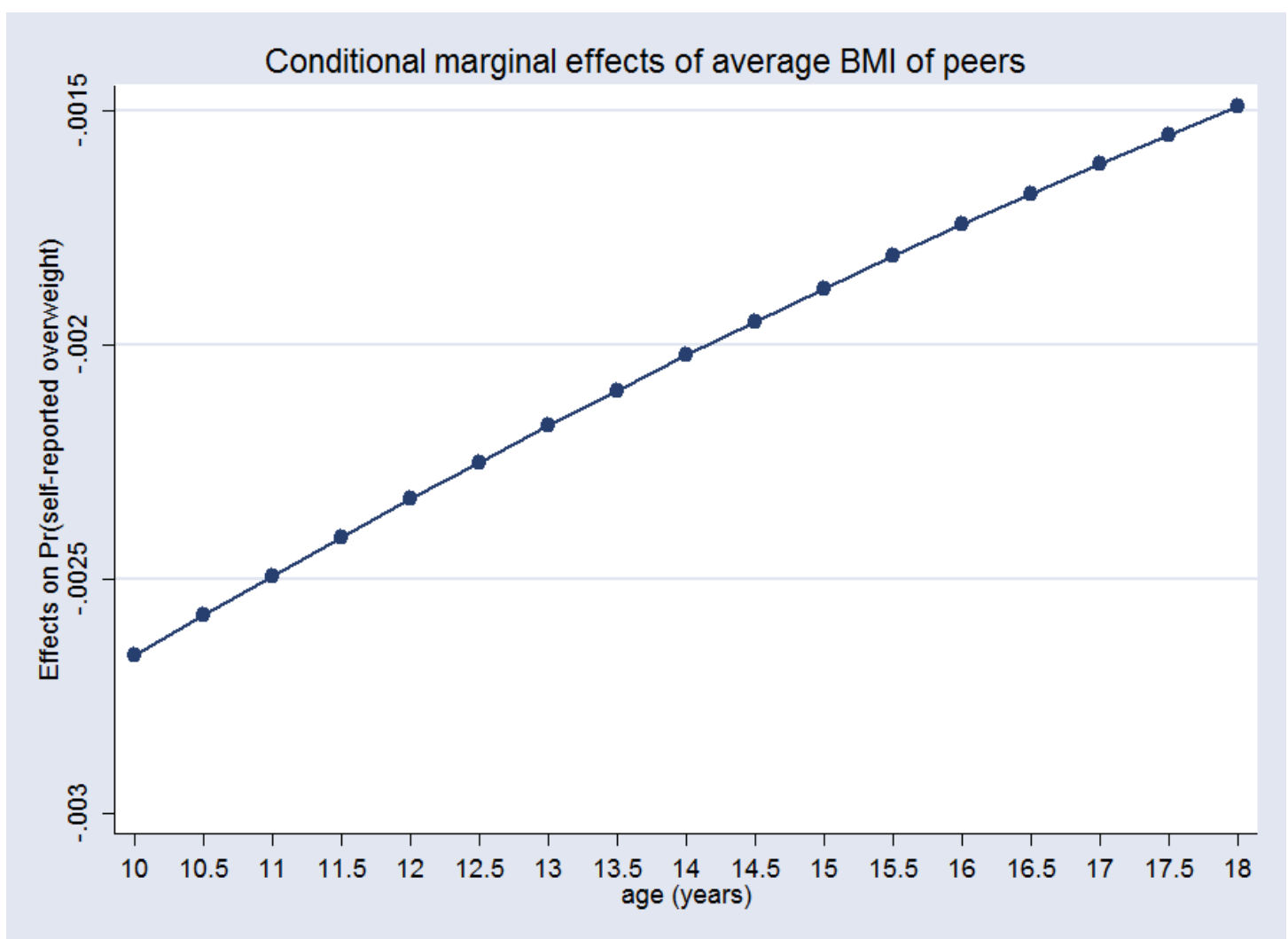

Figure A1 Marginal effects for different adolescent ages (10-18 years) 


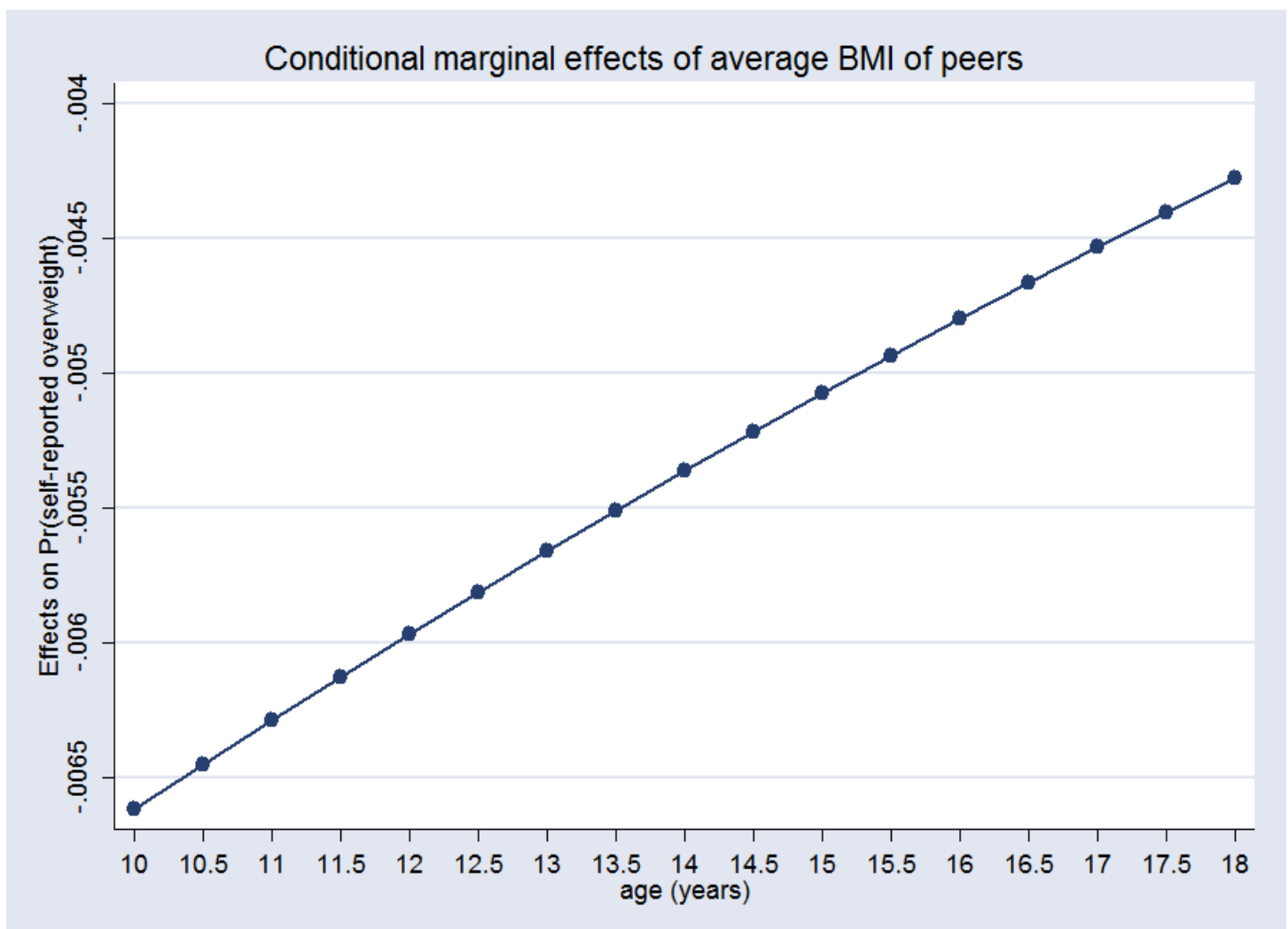

Figure A2 Marginal effects for different female adolescent ages (10-18 years)

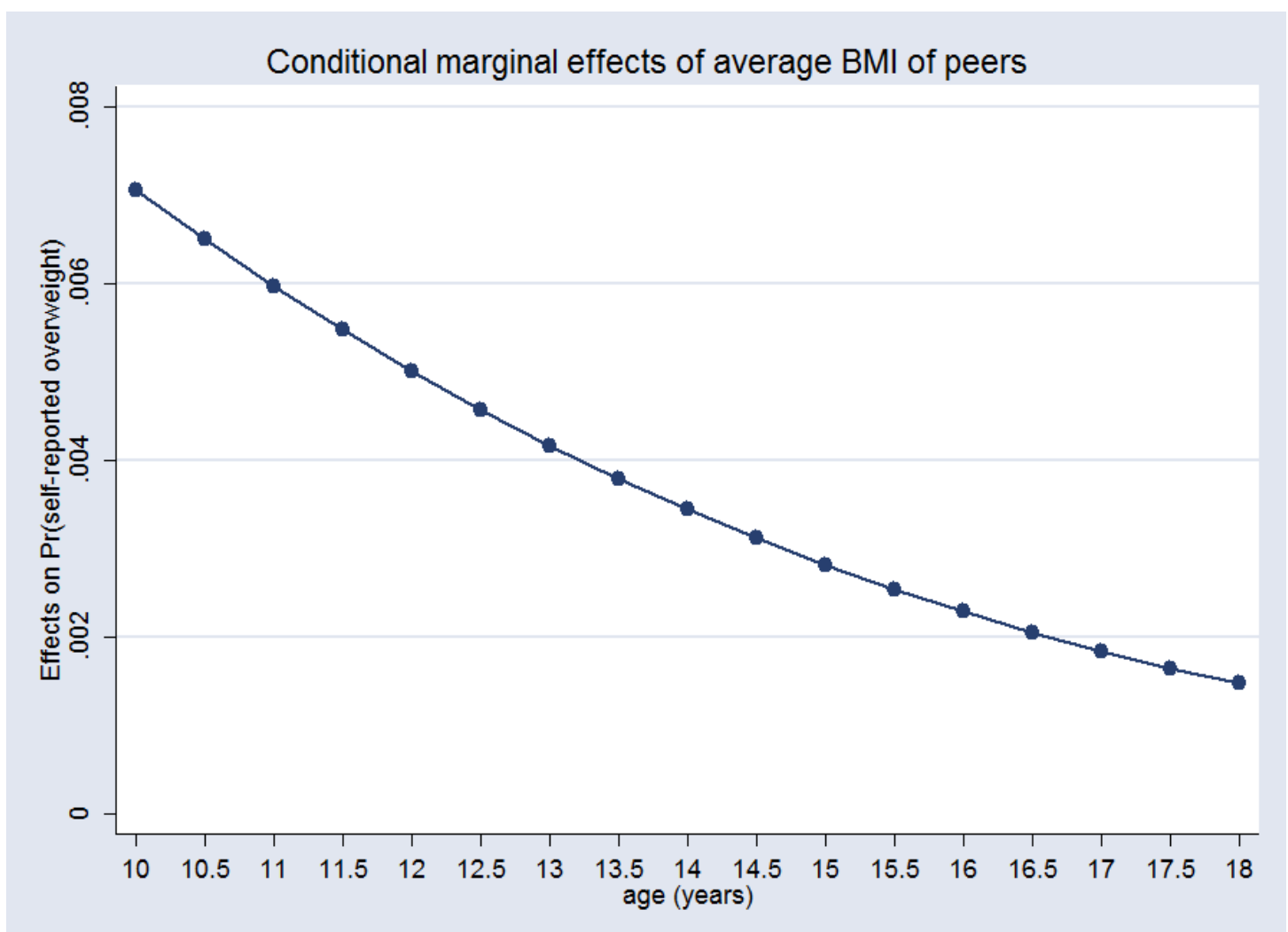

Figure A3 Marginal effects for different male adolescent ages (10-18 years) 


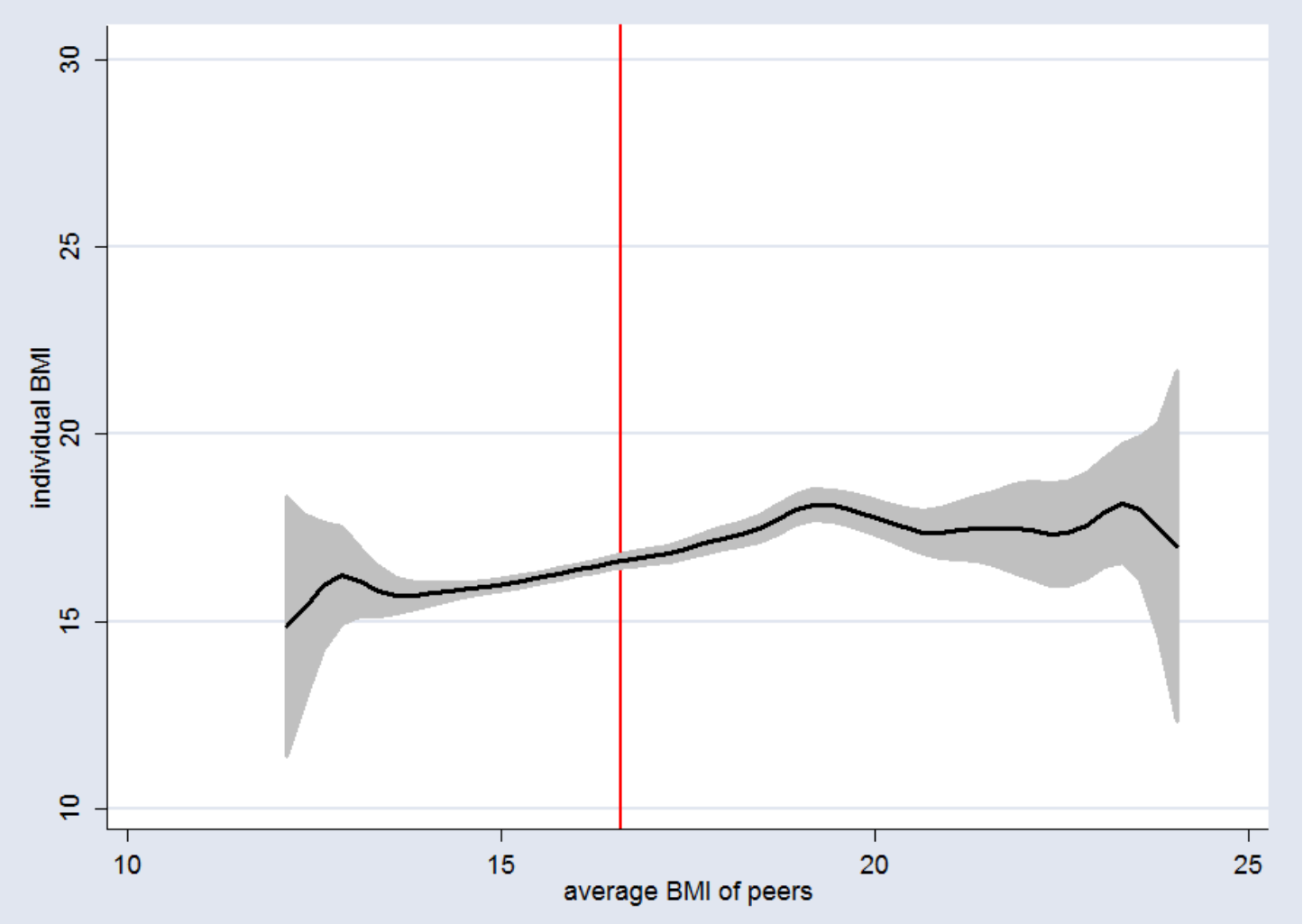

Figure A4: Semiparametric estimate of average peer effects (nonparametric part) Note: The red vertical line indicates the overall average peer BMI (16.61) in our sample. 
Table A2 OLS estimates of peer effects on individual bodyweight (double log model, 3- to 18year-olds)

\begin{tabular}{|c|c|c|c|c|c|c|c|}
\hline & $\begin{array}{l}\text { (1) } \\
\text { All }\end{array}$ & $\begin{array}{l}\text { (2) } \\
\text { All }\end{array}$ & $\begin{array}{l}\text { (3) } \\
\text { All }\end{array}$ & $\begin{array}{c}\text { (4) } \\
\text { Urban }\end{array}$ & $\begin{array}{c}(5) \\
\text { Rural }\end{array}$ & $\begin{array}{c}\text { (6) } \\
\text { Male }\end{array}$ & $\begin{array}{c}(7) \\
\text { Female }\end{array}$ \\
\hline $\begin{array}{l}\text { APB } \\
\text { (log) }\end{array}$ & $\begin{array}{c}0.596^{* * *} \\
(0.030)\end{array}$ & $\begin{array}{c}0.369^{* * * *} \\
(0.036)\end{array}$ & $\begin{array}{c}0.281^{* * *} \\
(0.039)\end{array}$ & $\begin{array}{c}0.153^{*} \\
(0.080)\end{array}$ & $\begin{array}{c}0.281^{* * * *} \\
(0.047)\end{array}$ & $\begin{array}{c}0.186^{* * *} \\
(0.050)\end{array}$ & $\begin{array}{c}0.367^{* * *} \\
(0.060)\end{array}$ \\
\hline CI & {$[0.537,0.655]$} & {$[0.299,0.440]$} & {$[0.204,0.359]$} & {$[-0.004,0.309]$} & {$[0.189,0.373]$} & {$[0.088,0.285]$} & {$[0.249,0.486]$} \\
\hline$N$ & 2186 & 2186 & 2186 & 528 & 1658 & 1191 & 995 \\
\hline $\operatorname{Adj} . R^{2}$ & 0.179 & 0.255 & 0.261 & 0.258 & 0.253 & 0.280 & 0.252 \\
\hline \multicolumn{8}{|c|}{ Children: 3-9years } \\
\hline $\begin{array}{l}\text { APB } \\
(\log )\end{array}$ & $\begin{array}{c}0.434^{* * *} \\
(0.049)\end{array}$ & $\begin{array}{c}0.360^{* * * *} \\
(0.050)\end{array}$ & $\begin{array}{c}0.253^{* * *} \\
(0.057)\end{array}$ & $\begin{array}{c}0.119 \\
(0.141)\end{array}$ & $\begin{array}{c}0.241^{* * *} \\
(0.065)\end{array}$ & $\begin{array}{l}0.171^{* *} \\
(0.072)\end{array}$ & $\begin{array}{c}0.342^{* * *} \\
(0.088)\end{array}$ \\
\hline CI & {$[0.338,0.530]$} & {$[0.262,0.459]$} & {$[0.142,0.364]$} & {$[-0.158,0.396]$} & {$[0.112,0.369]$} & {$[0.030,0.312]$} & {$[0.170,0.514]$} \\
\hline$N$ & 1237 & 1237 & 1237 & 303 & 934 & 685 & 552 \\
\hline $\operatorname{Adj} . R^{2}$ & 0.084 & 0.137 & 0.149 & 0.170 & 0.138 & 0.141 & 0.159 \\
\hline \multicolumn{8}{|c|}{ Adolescents: $10-18$ years } \\
\hline $\begin{array}{l}\text { APB } \\
(\log )\end{array}$ & $\begin{array}{c}0.529^{* * *} \\
(0.045)\end{array}$ & $\begin{array}{c}0.278^{* * *} \\
(0.053)\end{array}$ & $\begin{array}{l}0.140^{* *} \\
(0.058)\end{array}$ & $\begin{array}{c}-0.186 \\
(0.133)\end{array}$ & $\begin{array}{l}0.145^{* *} \\
(0.069)\end{array}$ & $\begin{array}{c}0.062 \\
(0.084)\end{array}$ & $\begin{array}{l}0.201^{* *} \\
(0.084)\end{array}$ \\
\hline CI & {$[0.441,0.617]$} & {$[0.173,0.382]$} & {$[0.026,0.254]$} & {$[-0.448,0.076]$} & {$[0.009,0.280]$} & {$[-0.103,0.227]$} & {$[0.037,0.366]$} \\
\hline$N$ & 949 & 949 & 949 & 225 & 724 & 506 & 443 \\
\hline Adj. $R^{2}$ & 0.135 & 0.226 & 0.237 & 0.145 & 0.250 & 0.249 & 0.251 \\
\hline
\end{tabular}

Note: The dependent variable is the translog BMI of children aged 3 to 18 years. All models are in log-log forms. APB=average peer BMI. (1) includes average peer BMI without control, (2) includes individual characteristics (age and gender), mother characteristics (mother's BMI, education, and employment status), and household characteristics (translog household net income, household size) as well as an urban dummy. (3) includes the same controls as (2) plus year dummies (with 2004 as the base year) and province dummies (with Liaoning as the base province), as well as dummies for public schools, fast food restaurants and recreational facilities in the community, and 20 different free market food prices (yuan/kilograms, inflated to 2011). (4) and (5) include the same controls as (3) but for urban and rural areas, respectively. (6) and (7) include the same controls as (3). CI $=95 \%$ confidence intervals; robust standard errors are in parentheses; ${ }^{*} p<0.1,{ }^{* *} p<0.05,{ }^{* * *} p<0.01$. 
Table A3 Quantile regressions of peer effects on individual bodyweight (double log model, 3- to 18-year-olds)

\begin{tabular}{lccc}
\hline & $25 \%$ & $50 \%$ & $75 \%$ \\
\hline Average peer BMI $(\log )$ & $0.233^{* * * *}$ & $0.310^{* * * *}$ & $0.359^{* * * *}$ \\
& $(0.042)$ & $(0.045)$ & $(0.061)$ \\
\hline CI & {$[0.151,0.315]$} & {$[0.221,0.399]$} & {$[0.239,0.479]$} \\
$N$ & 2186 & 2186 & 2186 \\
Pseudo $R^{2}$ & 0.150 & 0.186 & 0.206 \\
\hline Males & $25 \%$ & $50 \%$ & $75 \%$ \\
\hline Average peer BMI (log) & $0.278^{* * *}$ & $0.303^{* * *}$ & $0.267^{* * *}$ \\
& $(0.055)$ & $(0.059)$ & $(0.086)$ \\
\hline CI & {$[0.171,0.386]$} & {$[0.187,0.419]$} & {$[0.097,0.436]$} \\
$N$ & 1191 & 1191 & 1191 \\
Pseudo $R^{2}$ & 0.169 & 0.198 & 0.223 \\
\hline Females & $25 \%$ & $50 \%$ & $75 \%$ \\
\hline Average peer BMI (log) & $0.274^{* * * *}$ & $0.283^{* * * *}$ & 0.428 \\
& $(0.067)$ & $(0.077)$ & $(0.091)$ \\
\hline CI & {$[0.143,0.405]$} & {$[0.133,0.433]$} & {$[0.249,0.607]$} \\
$N$ & 995 & 995 & 995 \\
Pseudo $R^{2}$ & 0.159 & 0.203 & 0.212 \\
\hline
\end{tabular}

Note: The dependent variable is the translog BMI of children aged 3 to 18 years. All models are in log-log forms. Controls include individual characteristics (age and gender), mother characteristics (mother's BMI, education, and employment status), and household characteristics (translog household net income, household size), as well as an urban dummy, year dummies (with 2004 as the base year) and province dummies (with Liaoning as the base province), and dummies for public schools, fast food restaurants and recreational facilities in the community, and 20 different free market food prices (yuan/kilograms, inflated to 2011). CI $=95 \%$ confidence intervals; bootstrapped standard errors are in parentheses; ${ }^{*} p<0.1,{ }^{* *} p<0.05,{ }^{* * *} p<0.01$. 
Table A4 OLS estimates of peer effects on individual BMI (6- to 18-year-olds)

\begin{tabular}{lccccc}
\hline & $(1)$ & $(2)$ & $(3)$ & $(4)$ & $(5)$ \\
& All & All & All & Male & Female \\
\hline Average peer BMI & $0.584^{* * * *}$ & $0.406^{* * * *}$ & $0.325^{* * *}$ & 0.082 & $0.484^{* * *}$ \\
& $(0.046)$ & $(0.060)$ & $(0.065)$ & $(0.076)$ & $(0.091)$ \\
\hline CI & {$[0.494,0.674]$} & {$[0.288,0.525]$} & {$[0.197,0.452]$} & {$[-0.068,0.231]$} & {$[0.305,0.663]$} \\
$N$ & 1031 & 1031 & 1031 & 561 & 470 \\
Adj. $R^{2}$ & 0.182 & 0.248 & 0.258 & 0.258 & 0.302 \\
\hline & \multicolumn{5}{c}{ Children: 6-9years } \\
\hline Average peer BMI & $0.569^{* * * *}$ & $0.448^{* * *}$ & $0.390^{* * *}$ & -0.012 & $0.631^{* * *}$ \\
& $(0.083)$ & $(0.098)$ & $(0.105)$ & $(0.129)$ & $(0.127)$ \\
\hline CI & {$[0.405,0.732]$} & {$[0.255,0.642]$} & {$[0.183,0.597]$} & {$[-0.266,0.241]$} & {$[0.380,0.881]$} \\
$N$ & 459 & 459 & 459 & 257 & 202 \\
Adj. $R^{2}$ & 0.163 & 0.232 & 0.225 & 0.203 & 0.386 \\
\hline \multicolumn{5}{c}{ Adolescents: 10-18 years } \\
\hline Average peer BMI & $0.517^{* * * *}$ & $0.362^{* * *}$ & $0.227^{* * *}$ & 0.124 & $0.286^{* * *}$ \\
& $(0.056)$ & $(0.068)$ & $(0.070)$ & $(0.101)$ & $(0.102)$ \\
\hline CI & {$[0.406,0.627]$} & {$[0.229,0.495]$} & {$[0.089,0.365]$} & {$[-0.074,0.322]$} & {$[0.086,0.487]$} \\
$N$ & 572 & 572 & 572 & 304 & 268 \\
Adj. $R^{2}$ & 0.144 & 0.207 & 0.226 & 0.222 & 0.221 \\
\hline
\end{tabular}

Note: Sample size is restricted to respondents aged 6 to 18. Peers are defined in the same age band and at the same school and community level. (1) includes average peer BMI, (2) includes individual characteristics (age and gender), mother characteristics (mother's BMI, education, and employment status), and household characteristics (translog household net income, household size), as well as an urban dummy. (3) includes the same controls as (2) plus year dummies (with 2004 as the base year) and province dummies (with Liaoning as the base province), and dummies for public schools, fast food restaurants and recreational facilities in the community, and 20 different free market food prices (yuan/kilograms, inflated to 2011). (4) and (5) include the same controls as (3). CI $=95 \%$ confidence intervals; robust standard errors are in parentheses; ${ }^{*} p<0.1,{ }^{* *} p<0.05,{ }^{* * *} p<0.01$. 
Table A5 Quantile regressions of peer effects on individual BMI (6- to 18-year-olds)

\begin{tabular}{lccc}
\hline & $25 \%$ & $50 \%$ & $75 \%$ \\
\hline Average peer BMI & $0.121^{* *}$ & $0.257^{* * * *}$ & $0.330^{* * *}$ \\
& $(0.049)$ & $(0.082)$ & $(0.086)$ \\
\hline CI & {$[0.024,0.217]$} & {$[0.097,0.418]$} & {$[0.161,0.500]$} \\
$N$ & 1031 & 1031 & 1031 \\
Pseudo $R^{2}$ & 0.182 & 0.207 & 0.219 \\
\hline Males & $25 \%$ & $50 \%$ & $75 \%$ \\
\hline Average peer BMI & 0.062 & 0.121 & 0.166 \\
& $(0.072)$ & $(0.098)$ & $(0.121)$ \\
\hline CI & {$[-0.080,0.204]$} & {$[-0.072,0.313]$} & {$[-0.072,0.405]$} \\
$N$ & 561 & 561 & 561 \\
Pseudo $R^{2}$ & 0.207 & 0.221 & 0.238 \\
\hline Females & $25 \%$ & $50 \%$ & $75 \%$ \\
\hline Average peer BMI & $0.217^{* *}$ & $0.359^{* * * *}$ & $0.510^{* * *}$ \\
& $(0.088)$ & $(0.121)$ & $(0.124)$ \\
\hline CI & {$[0.045,0.390]$} & {$[0.122,0.596]$} & {$[0.266,0.754]$} \\
$N$ & 470 & 470 & 470 \\
Pseudo $R^{2}$ & 0.225 & 0.244 & 0.279 \\
\hline
\end{tabular}

Note: Peers are defined as those in the same age band and at the same school and community level. Controls include individual characteristics (age and gender), mother characteristics (mother's BMI, education, and employment status), and household characteristics (household per capita income, household size), as well as an urban dummy, year dummies (with 2004 as the base year) and province dummies (with Liaoning as the base province), and dummies for public schools (primary school, lower middle school and upper middle school), fast food restaurants and recreational facilities (gym/exercise centers, park/public recreation places, playgrounds) in the community, and 20 different free market food prices (yuan/kilograms, inflated to 2011). CI $=95 \%$ confidence intervals; bootstrapped standard errors are in parentheses; ${ }^{*} p<0.1,{ }^{* *} p<0.05,{ }^{* * *} p<0.01$. 
Table A6 OLS estimates of same-gender peer effects on individual BMI (3- to 18-year-olds)

\begin{tabular}{|c|c|c|c|c|c|}
\hline & $\begin{array}{l}\text { (1) } \\
\text { All }\end{array}$ & $\begin{array}{l}\text { (2) } \\
\text { All }\end{array}$ & $\begin{array}{l}\text { (3) } \\
\text { All }\end{array}$ & $\begin{array}{c}(4) \\
\text { Male }\end{array}$ & $\begin{array}{c}(5) \\
\text { Female }\end{array}$ \\
\hline Average peer BMI & $\begin{array}{c}0.544^{* * *} \\
(0.042)\end{array}$ & $\begin{array}{l}0.358^{* * * *} \\
(0.048)\end{array}$ & $\begin{array}{c}0.283^{* * *} \\
(0.051)\end{array}$ & $\begin{array}{l}0.156^{* *} \\
(0.063)\end{array}$ & $\begin{array}{c}0.335^{* * *} \\
(0.080)\end{array}$ \\
\hline $\mathrm{CI}$ & {$[0.462,0.626]$} & {$[0.265,0.452]$} & {$[0.183,0.384]$} & {$[0.032,0.280]$} & {$[0.178,0.493]$} \\
\hline$N$ & 1566 & 1566 & 1566 & 905 & 661 \\
\hline Adj. $R^{2}$ & 0.162 & 0.240 & 0.249 & 0.256 & 0.242 \\
\hline \multicolumn{6}{|c|}{ Children: 3-9 years } \\
\hline Average peer BMI & $\begin{array}{c}0.461^{* * * *} \\
(0.071)\end{array}$ & $\begin{array}{c}0.381^{* * *} \\
(0.070)\end{array}$ & $\begin{array}{c}0.312^{* * *} \\
(0.076)\end{array}$ & $\begin{array}{c}0.149^{*} \\
(0.087)\end{array}$ & $\begin{array}{c}0.375^{* * * *} \\
(0.119)\end{array}$ \\
\hline CI & {$[0.322,0.599]$} & {$[0.244,0.519]$} & {$[0.163,0.461]$} & {$[-0.023,0.320]$} & {$[0.141,0.609]$} \\
\hline$N$ & 895 & 895 & 895 & 531 & 364 \\
\hline Adj. $R^{2}$ & 0.105 & 0.160 & 0.162 & 0.154 & 0.199 \\
\hline \multicolumn{6}{|c|}{ Adolescents: $10-18$ years } \\
\hline Average peer BMI & $\begin{array}{l}0.450 \\
(0.059)\end{array}$ & $\begin{array}{l}0.265^{* * *} \\
(0.065)\end{array}$ & $\begin{array}{c}0.109 \\
(0.067)\end{array}$ & $\begin{array}{c}-0.009 \\
(0.103)\end{array}$ & $\begin{array}{c}-0.024 \\
(0.092)\end{array}$ \\
\hline CI & {$[0.334,0.565]$} & {$[0.137,0.394]$} & {$[-0.024,0.241]$} & {$[-0.213,0.194]$} & {$[-0.205,0.158]$} \\
\hline$N$ & 671 & 671 & 671 & 374 & 297 \\
\hline Adj. $R^{2}$ & 0.110 & 0.198 & 0.221 & 0.224 & 0.244 \\
\hline
\end{tabular}

Note: The dependent variable is the BMI of children aged 3 to 18. Peers are defined as those in the same age group and community and of the same gender. (1) includes average peer BMI, (2) includes individual characteristics (age and gender), mother characteristics (mother's BMI, education, and employment status), and household characteristics (translog household net income, household size), as well as an urban dummy. (3) includes the same controls as (2) plus year dummies (with 2004 as the base year) and province dummies (with Liaoning as the base province), and dummies for public schools, fast food restaurants and recreational facilities in the community, and 20 different free market food prices (yuan/kilograms, inflated to 2011). (4) and (5) include the same controls as (3). CI $=95 \%$ confidence intervals; robust standard errors are in parentheses; ${ }^{*} p<0.1,{ }^{* *} p<0.05,{ }^{* * *} p<0.01$. 
Table A7 Quantile regressions of same-gender peer effects on individual BMI (3- to 18-year-olds)

\begin{tabular}{lccc}
\hline & $25 \%$ & $50 \%$ & $75 \%$ \\
\hline Average peer BMI & $0.198^{* * * *}$ & $0.334^{* * * *}$ & $0.317^{* * *}$ \\
& $(0.050)$ & $(0.047)$ & $(0.068)$ \\
\hline CI & {$[0.099,0.297]$} & {$[0.242,0.427]$} & {$[0.183,0.451]$} \\
$N$ & 1566 & 1566 & 1566 \\
Pseudo $R^{2}$ & 0.130 & 0.174 & 0.215 \\
\hline Males & $25 \%$ & $50 \%$ & $75 \%$ \\
\hline Average peer BMI & $0.188^{* * *}$ & $0.287^{* * *}$ & $0.226^{* *}$ \\
& $(0.069)$ & $(0.068)$ & $(0.090)$ \\
\hline CI & {$[0.053,0.324]$} & {$[0.154,0.421]$} & {$[0.050,0.402]$} \\
$N$ & 905 & 905 & 905 \\
Pseudo $R^{2}$ & 0.150 & 0.188 & 0.233 \\
\hline Females & $25 \%$ & $50 \%$ & $75 \%$ \\
\hline Average peer BMI & $0.211^{* * *}$ & $0.263^{* * *}$ & $0.344^{* * *}$ \\
& $(0.075)$ & $(0.086)$ & $(0.126)$ \\
\hline CI & {$[0.063,0.359]$} & {$[0.094,0.431]$} & {$[0.096,0.592]$} \\
$N$ & 661 & 661 & 661 \\
Pseudo $R^{2}$ & 0.152 & 0.186 & 0.239 \\
\hline
\end{tabular}

Note: The dependent variable is the BMI of children aged 3 to 18. Peers are defined as those in the same age group and community and of the same gender. Controls include individual characteristics (age and gender), mother characteristics (mother's BMI, education, and employment status), and household characteristics (translog household net income, household size), as well as an urban dummy, year dummies (with 2004 as the base year) and province dummies (with Liaoning as the base province), and dummies for public schools, fast food restaurants and recreational facilities, and 20 different free market food prices (yuan/kilograms, inflated to 2011). CI $=95 \%$ confidence intervals; bootstrapped standard errors are in parentheses; ${ }^{*} p<0.1,{ }^{* *} p<0.05,{ }^{* * *} p<0.01$. 
Table A8 OLS estimates of peer effects on individual bodyweight (using z-score; 3- to 18-yearolds)

\begin{tabular}{|c|c|c|c|c|c|c|c|}
\hline & $\begin{array}{l}\text { (1) } \\
\text { All }\end{array}$ & $\begin{array}{l}\text { (2) } \\
\text { All }\end{array}$ & $\begin{array}{l}\text { (3) } \\
\text { All }\end{array}$ & $\begin{array}{c}(4) \\
\text { Urban }\end{array}$ & $\begin{array}{c}\text { (5) } \\
\text { Rural }\end{array}$ & $\begin{array}{c}\text { (6) } \\
\text { Male }\end{array}$ & $\begin{array}{c}(7) \\
\text { Female }\end{array}$ \\
\hline APB & $\begin{array}{c}0.128^{* * *} \\
(0.013)\end{array}$ & $\begin{array}{c}0.143^{* * *} \\
(0.017)\end{array}$ & $\begin{array}{c}0.097^{* * *} \\
(0.018)\end{array}$ & $\begin{array}{c}0.052 \\
(0.037)\end{array}$ & $\begin{array}{c}0.092^{* * *} \\
(0.022)\end{array}$ & $\begin{array}{l}0.061^{* *} \\
(0.024)\end{array}$ & $\begin{array}{c}0.125^{* * *} \\
(0.027)\end{array}$ \\
\hline CI & {$[0.102,0.155]$} & {$[0.111,0.176]$} & {$[0.061,0.132]$} & {$[-0.020,0.124]$} & {$[0.049,0.134]$} & $\begin{array}{l}{[0.014,0.107]} \\
\end{array}$ & {$[0.073,0.178]$} \\
\hline$N$ & 2186 & 2186 & 2186 & 528 & 1658 & 1191 & 995 \\
\hline Adj. $R^{2}$ & 0.041 & 0.135 & 0.149 & 0.133 & 0.148 & 0.147 & 0.167 \\
\hline \multicolumn{8}{|c|}{ Children: 3-9 years } \\
\hline APB & $\begin{array}{l}0.209^{* * * *} \\
(0.025)\end{array}$ & $\begin{array}{l}0.177^{* * *} \\
(0.026)\end{array}$ & $\begin{array}{l}0.111^{* * *} \\
(0.028)\end{array}$ & $\begin{array}{c}0.061 \\
(0.067) \\
\end{array}$ & $\begin{array}{c}0.098^{* * *} \\
(0.033)\end{array}$ & $\begin{array}{l}0.087^{* *} \\
(0.036) \\
\end{array}$ & $\begin{array}{l}0.132^{* * *} \\
(0.043)\end{array}$ \\
\hline CI & {$[0.160,0.258]$} & {$[0.127,0.227]$} & {$[0.056,0.165]$} & {$[-0.072,0.193]$} & {$[0.034,0.162]$} & $\begin{array}{l}{[0.016,0.158]} \\
\end{array}$ & {$[0.048,0.217]$} \\
\hline$N$ & 1237 & 1237 & 1237 & 303 & 934 & 685 & 552 \\
\hline Adj. $R^{2}$ & 0.066 & 0.132 & 0.155 & 0.179 & 0.151 & 0.141 & 0.173 \\
\hline \multicolumn{8}{|c|}{ Adolescents: $10-18$ years } \\
\hline APB & $\begin{array}{c}0.135^{* * *} \\
(0.018)\end{array}$ & $\begin{array}{c}0.107^{* * *} \\
(0.022)\end{array}$ & $\begin{array}{l}0.049^{* *} \\
(0.025)\end{array}$ & $\begin{array}{c}-0.056 \\
(0.050)\end{array}$ & $\begin{array}{c}0.049 \\
(0.030)\end{array}$ & $\begin{array}{c}0.013 \\
(0.037)\end{array}$ & $\begin{array}{l}0.077^{* *} \\
(0.033)\end{array}$ \\
\hline CI & {$[0.100,0.171]$} & {$[0.064,0.151]$} & {$[0.001,0.098]$} & {$[-0.155,0.044]$} & {$[-0.010,0.109]$} & {$[-0.060,0.086]$} & {$[0.012,0.141]$} \\
\hline$N$ & 949 & 949 & 949 & 225 & 724 & 506 & 443 \\
\hline Adj. $R^{2}$ & 0.057 & 0.151 & 0.166 & 0.101 & 0.171 & 0.178 & 0.162 \\
\hline
\end{tabular}

Note: The dependent variable is the (IOTF) z-score of BMI for children aged 3-18 years. APB= average peer BMI. (1) includes average peer BMI without controls, (2) includes individual characteristics (age and gender), mother characteristics (mother's BMI, education, and employment status), and household characteristics (translog household net income, household size), as well as an urban dummy. (3) includes the same controls as (2) plus year dummies (with 2004 as the base year) and province dummies (with Liaoning as the base province), and dummies for public schools, fast food restaurants and recreational facilities in the community, and 20 different free market food prices (yuan/kilograms, inflated to 2011). (4) - (7) include the same controls as (3). CI $=95 \%$ confidence intervals; robust standard errors are in parentheses; ${ }^{*} p<0.1,{ }^{* *} p<0.05,{ }^{* * *} p<0.01$ 
Table A9 Quantile regressions of peer effects on individual bodyweight (using z-score, 3- to 18year-olds)

\begin{tabular}{lccc}
\hline & $25 \%$ & $50 \%$ & $75 \%$ \\
\hline Average peer BMI & $0.076^{* * * *}$ & $0.100^{* * * *}$ & $0.112^{* * * *}$ \\
& $(0.021)$ & $(0.023)$ & $(0.026)$ \\
\hline CI & {$[0.035,0.116]$} & {$[0.054,0.146]$} & {$[0.061,0.164]$} \\
$N$ & 2186 & 2186 & 2186 \\
Pseudo $R^{2}$ & 0.092 & 0.109 & 0.129 \\
\hline Males & $25 \%$ & $50 \%$ & $75 \%$ \\
\hline Average peer BMI & $0.064^{* *}$ & $0.095^{* * *}$ & $0.066^{*}$ \\
& $(0.029)$ & $(0.032)$ & $(0.034)$ \\
\hline CI & {$[0.007,0.121]$} & {$[0.033,0.157]$} & {$[-0.002,0.133]$} \\
$N$ & 1191 & 1191 & 1191 \\
Pseudo $R^{2}$ & 0.115 & 0.124 & 0.134 \\
\hline Females & $25 \%$ & $50 \%$ & $75 \%$ \\
\hline Average peer BMI & $0.101^{* * * *}$ & $0.104^{* * *}$ & $0.141^{* * *}$ \\
& $(0.031)$ & $(0.028)$ & $(0.034)$ \\
\hline CI & {$[0.040,0.162]$} & {$[0.049,0.160]$} & {$[0.075,0.207]$} \\
$N$ & 995 & 995 & 995 \\
Pseudo $R^{2}$ & 0.103 & 0.127 & 0.158 \\
\hline
\end{tabular}

Note: The dependent variable is (IOTF) z-scores of BMI for children aged 3-18 years. Controls include individual characteristics (age and gender), mother characteristics (mother's BMI, education, and employment status), and household characteristics (translog household net income, household size), as well as an urban dummy, year dummies (with 2004 as the base year) and province dummies (with Liaoning as the base province), and dummies for public schools, fast food restaurants and recreational facilities in the community, and 20 different free market food prices (yuan/kilograms, inflated to 2011). CI =95\% confidence intervals; bootstrapped standard errors are in parentheses; ${ }^{*} p<0.1, \stackrel{* *}{p}<0.05,{ }^{* * *} p<0.01$. 
Table A10 OLS estimates of peer effects on individual bodyweight (using waist circumference, 3to 18-year-olds)

\begin{tabular}{|c|c|c|c|c|c|}
\hline & (1) & (2) & (3) & (4) & (5) \\
\hline & All & All & All & Male & Female \\
\hline Average peer WC & $\begin{array}{c}0.674^{* * *} \\
(0.030)\end{array}$ & $\begin{array}{c}0.217^{* * *} \\
(0.039)\end{array}$ & $\begin{array}{l}0.103^{* *} \\
(0.046)\end{array}$ & $\begin{array}{c}0.030 \\
(0.062)\end{array}$ & $\begin{array}{c}0.188^{* * *} \\
(0.068)\end{array}$ \\
\hline $\mathrm{CI}$ & {$[0.615,0.734]$} & {$[0.140,0.294]$} & {$[0.013,0.193]$} & {$[-0.093,0.152]$} & {$[0.055,0.322]$} \\
\hline$N$ & 1608 & 1608 & 1608 & 874 & 734 \\
\hline Adj. $R^{2}$ & 0.236 & 0.372 & 0.387 & 0.368 & 0.393 \\
\hline \multicolumn{6}{|c|}{ Children: 3-9 years } \\
\hline Average peer WC & $\begin{array}{c}0.294^{* * * *} \\
(0.056)\end{array}$ & $\begin{array}{c}0.125^{*} \\
(0.064)\end{array}$ & $\begin{array}{c}0.017 \\
(0.078)\end{array}$ & $\begin{array}{c}-0.058 \\
(0.104)\end{array}$ & $\begin{array}{c}0.108 \\
(0.116)\end{array}$ \\
\hline $\mathrm{CI}$ & {$[0.184,0.403]$} & {$[-0.001,0.252]$} & {$[-0.137,0.171]$} & {$[-0.263,0.146]$} & {$[-0.120,0.336]$} \\
\hline$N$ & 678 & 678 & 678 & 379 & 299 \\
\hline Adj. $R^{2}$ & 0.041 & 0.112 & 0.125 & 0.122 & 0.095 \\
\hline \multicolumn{6}{|c|}{ Adolescents: $10-18$ years } \\
\hline Average peer WC & $\begin{array}{l}0.572^{* * * *} \\
(0.043)\end{array}$ & $\begin{array}{l}0.264^{* * * *} \\
(0.049)\end{array}$ & $\begin{array}{l}0.120^{* *} \\
(0.058)\end{array}$ & $\begin{array}{c}0.037 \\
(0.082)\end{array}$ & $\begin{array}{l}0.200^{* *} \\
(0.089)\end{array}$ \\
\hline $\mathrm{CI}$ & {$[0.488,0.656]$} & {$[0.169,0.359]$} & {$[0.006,0.235]$} & {$[-0.125,0.198]$} & {$[0.026,0.375]$} \\
\hline$N$ & 930 & 930 & 930 & 495 & 435 \\
\hline Adj. $R^{2}$ & 0.157 & 0.272 & 0.293 & 0.268 & 0.316 \\
\hline
\end{tabular}

Note: The dependent variable is waist circumference (WC) in cm. (1) includes average peer waist circumference, (2) includes individual characteristics (age and gender), mother characteristics (mother's BMI, education, and employment status), and household characteristics (translog household net income, household size), as well as an urban dummy. (3) includes the same controls as (2) plus year dummies (with 2004 as the base year) and province dummies (with Liaoning as the base province), and dummies for public schools, fast food restaurants and recreational facilities in the community, and 20 different free market food prices (yuan/kilograms, inflated to 2011). (4) and (5) include the same controls as (3). CI $=95 \%$ confidence intervals; robust standard errors are in parentheses; ${ }^{*} p<0.1, \stackrel{* *}{p}<0.05, \stackrel{* * *}{p}<0.01$. 
Table A11 Quantile regressions of peer effects on individual bodyweight (using waist circumference, 3- to 18-year-olds)

\begin{tabular}{|c|c|c|c|}
\hline & $25 \%$ & $50 \%$ & $75 \%$ \\
\hline \multirow[t]{2}{*}{ Average peer WC } & 0.073 & $0.103^{* *}$ & $0.110^{* *}$ \\
\hline & (0.069) & $(0.044)$ & $(0.052)$ \\
\hline $\mathrm{CI}$ & {$[-0.063,0.209]$} & {$[0.017,0.189]$} & {$[0.009,0.212]$} \\
\hline$N$ & 1608 & 1608 & 1608 \\
\hline Pseudo $R^{2}$ & 0.237 & 0.268 & 0.272 \\
\hline Males & $25 \%$ & $50 \%$ & $75 \%$ \\
\hline \multirow{2}{*}{ Average peer WC } & 0.074 & 0.053 & 0.008 \\
\hline & $(0.077)$ & $(0.062)$ & $(0.096)$ \\
\hline $\mathrm{CI}$ & {$[-0.077,0.225]$} & {$[-0.069,0.175]$} & {$[-0.179,0.196]$} \\
\hline$N$ & 874 & 874 & 874 \\
\hline Pseudo $R^{2}$ & 0.238 & 0.271 & 0.282 \\
\hline Females & $25 \%$ & $50 \%$ & $75 \%$ \\
\hline \multirow[t]{2}{*}{ Average peer WC } & 0.048 & $0.195^{* * 4}$ & $0.176^{*}$ \\
\hline & (0.099) & $(0.090)$ & $(0.091)$ \\
\hline CI & {$[-0.146,0.242]$} & {$[0.018,0.372]$} & {$[-0.003,0.355]$} \\
\hline$N$ & 734 & 734 & 734 \\
\hline Pseudo $R^{2}$ & 0.261 & 0.283 & 0.297 \\
\hline
\end{tabular}

Note: The dependent variable is waist circumference (WC). Controls include individual characteristics (age and gender), mother characteristics (mother's BMI, education, and employment status), and household characteristics (translog household net income, household size), as well as an urban dummy, year dummies (with 2004 as the base year) and province dummies (with Liaoning as the base province), and dummies for public schools, fast food restaurants and recreational facilities in the community, and 20 different free market food prices (yuan/kilograms, inflated to 2011). CI $=95 \%$ confidence intervals; bootstrapped standard errors are in parentheses; ${ }^{*} p<0.1,{ }^{* *} p<0.05$, ${ }^{* * * *}<0.01$. 